\title{
A novel role for phospholipase $D$ as an endogenous negative regulator of platelet sensitivity
}

\author{
Margitta Elvers, Magnus Grenegård, Hanieh Khoshjabinzadeh, Patrick Muenzer, \\ Oliver Borst, Huasong Tian, Gilbert Di Paolo, Florian Lang, Meinrad Gawaz, \\ Tomas Lindahl and Knut Fälker
}

\section{Linköping University Post Print}

N.B.: When citing this work, cite the original article.

Original Publication:

Margitta Elvers, Magnus Grenegård, Hanieh Khoshjabinzadeh, Patrick Muenzer, Oliver Borst, Huasong Tian, Gilbert Di Paolo, Florian Lang, Meinrad Gawaz, Tomas Lindahl and Knut Fälker, A novel role for phospholipase D as an endogenous negative regulator of platelet sensitivity, 2012, Cellular Signalling, (24), 9, 1743-1752.

http://dx.doi.org/10.1016/j.cellsig.2012.04.018

Copyright: Elsevier http://www.elsevier.com/

Postprint available at: Linköping University Electronic Press http://urn.kb.se/resolve?urn=urn:nbn:se:liu:diva-80685 


\section{A novel role for phospholipase $D$ as an endogenous negative regulator of platelet sensitivity}

Margitta Elvers ${ }^{1 *}$, Magnus Grenegård ${ }^{2}$, Hanieh Khoshjabinzadeh ${ }^{3}$, Patrick Münzer $^{4}$, Oliver Borst $^{1,4}$, Huasong Tian ${ }^{5}$, Gilbert Di Paolo ${ }^{5}$, Florian Lang ${ }^{4}$, Meinrad Gawaz ${ }^{1}$; Tomas L. Lindahl $^{3} \&$ Knut Fälker ${ }^{3}$

${ }^{1}$ Medizinische Klinik III, Dept. of Cardiology and Cardiovascular Diseases, Eberhard Karls University, Tübingen, Germany, ${ }^{2}$ University of Linköping, Faculty of Health Sciences, Department of Medicine and Health, Division of Drug Research/Pharmacology, and ${ }^{3}$ Department of Clinical and Experimental Medicine, Division of Clinical Chemistry, 58185 Linköping, Sweden, ${ }^{4}$ Department of Physiology, Eberhard Karls University, Tübingen, Germany, ${ }^{5}$ Columbia University Medical Center, Department of Pathology and Cell Biology, Taub Institute for Research on Alzheimer's Disease and the Aging Brain, New York, NY 10032, USA.

Running title: PLD as negative regulator in platelets

Key words: PLD, platelets, secretion, aggregation, regulation

Word count: 5.819

Abstract word count: 244

${ }^{*}$ Address correspondence to:

Margitta Elvers, Ph.D.

Medizinische Klinik und Poliklinik

Abteilung Innere Medizin III / Kardiologie und Kreislauferkrankungen

Eberhard Karls Universität Tübingen

Otfried-Müller Str. 10

72076 Tübingen

Phone: + 4970712982907

Fax: +49-7071-295749

E-mail: margitta.elvers@med.uni-tuebingen.de 


\section{Abstract}

Platelet aggregation, secretion and thrombus formation play a critical role in primary hemostasis to prevent excessive blood loss. On the other hand, uncontrolled platelet activation leads to pathological thrombus formation resulting in myocardial infarction or stroke. Stimulation of heterotrimeric G-proteins by soluble agonists or immunoreceptor tyrosine based activation motif-coupled receptors that interact with immobilized ligands such as the collagen receptor glycoprotein (GP) VI lead to the activation of phospholipases that cleave membrane phospholipids to generate soluble second messengers. Platelets contain the phospholipase (PL) D1 and D2 which catalyze the hydrolysis of phosphatidylcholine to generate the second messenger phosphatidic acid (PA). The production of PA is abrogated by primary alcohols that have been widely used for the analysis of PLD-mediated processes. However, it is not clear if primary alcohols effectively reduce PA generation or if they induce PLD-independent cellular effects. In the present study we made use of the specific PLD inhibitor 5-fluoro-2-indolyl des-chlorohalopemide (FIPI) and show for the first time, that FIPI enhances platelet dense granule secretion and aggregation of human platelets. Further, FIPI has no effect on cytosolic $\mathrm{Ca}^{2+}$ activity but needs proper Rho kinase signaling to mediate FIPI-induced effects on platelet activation. Upon FIPI treatment the phosphorylation of the PKC substrate pleckstrin was prominently enhanced suggesting that FIPI affects PKCmediated secretion and aggregation in platelets. Similar effects of FIPI were observed in platelets from mouse wild-type and Pld1\% mice pointing to a new role for PLD2 as negative regulator of platelet sensitivity. 


\section{Introduction}

Platelets, small anucleated cells produced by bone marrow megakaryocytes, circulate in the blood as sentinels of vascular integrity. At sites of vascular damage they rapidly adhere to the exposed sub-endothelial matrix, aggregate, and form a thrombus to seal the injury; and, as such, play a pivotal role in primary hemostasis to prevent bleeding and blood loss $[1 ; 2]$. On the other hand, inappropriate platelet aggregation and thrombus formation may lead to vascular occlusions resulting in myocardial infarction or stroke [3;4].

Platelet activation induced by a primary agonist, such as collagen or thrombin, leads to the generation and liberation of thromboxane $A_{2}\left(T X A_{2}\right)$ as well as to the secretion of alpha- and dense granules, the latter embodies the adenine nucleotides ATP and ADP. Once released, these secondary mediators amplify platelet activation via their respective receptors finally leading to the activation of integrin $\alpha_{\| 1 b} \beta_{3}$, which provides the molecular basis for platelets forming fibrinogen-bridged aggregates [4;5]. The subendothelial matrixprotein collagen activates platelets mainly via glycoprotein (GP) $\mathrm{VI}$, which induces via FcR a signaling cascade involving tyrosine kinases such as src and syk as well as phospholipase (PLC) $\gamma 2$ [6]. The serine-protease thrombin triggers the activation of human platelets via proteaseactivated receptors (PARs) 1 and 4 . These proteins belong to the family of G protein-coupled receptors (GPCRs) that act via $\mathrm{G}_{12 / 13}$ and $\mathrm{G} \alpha_{q}$ [7;8]. Although PAR-1 and PAR-4 are coupled with the same G-protein subtypes, they appear to exhibit differential affinities for thrombin and durations of intracellular signaling [9]. In contrast mouse platelets express PAR-3 and PAR-4, whereby PAR-3 does not induce intercellular signaling but serves as a co-factor for PAR-4 [8]. Whereas $\mathrm{Ga}_{12 / 13}$ signaling accounts for instant cytoskeletal reorganization (platelet 'shape change') via calcium/calmodulin and Rho/Rho-kinase signaling [10;11], $\mathrm{Ga}_{\mathrm{q}}$ signaling induces PLC isoform $\beta$ activation [12]. Activated PLC $\beta$ and $\gamma 2$ cleave phosphatidylinositol 4,5-bisphosphate $\left(\mathrm{PIP}_{2}\right)$ into diacylglycerol (DAG) and inositol 1,4,5-trisphosphate $\left(\mathrm{IP}_{3}\right)[13] . \mathrm{IP}_{3}$ triggers the release of $\mathrm{Ca}^{2+}$ from intracellular stores which in concert with DAG activates protein kinase C (PKC), a protein implicated in platelet granule 
secretion [12-14]. Furthermore, an increase in intracellular $\mathrm{Ca}^{2+}$ also accounts for activation

of phospholipase $A 2$ leading to the release of arachidonic acid which converted to $\mathrm{TXA}_{2}$ in a cyclooxygenase-dependent manner. For $\mathrm{TXA}_{2}$ the thromboxane/prostanoid receptor $\alpha$ (TP $\left.\alpha\right)$ is the predominant isoform in platelets and, like PAR-1 and PAR-4, is coupled with $\mathrm{G}_{12 / 13}$ and $G \alpha_{q}[15 ; 16]$. Whereas intermediate $\mathrm{TXA}_{2}$ signaling supports platelet activation and aggregation specifically at low concentrations of thrombin, dense granule secretion and therefore aggregation in response to high concentrations of collagen markedly relies on $\mathrm{TXA}_{2}$ synthesis and signaling [17].

For ADP the $G \alpha_{q}$-coupled $P_{2} Y_{1}$ receptors and $G \alpha_{i 2}$-coupled $P_{2} Y_{12}$ receptors have been identified on platelets [18;19]. The $\beta / \gamma$-subunits of $G \alpha_{i}$ directly induce phospoinositol-3-kinase (PI3-K) leading to an enhancement of granule secretion and activation of integrin $\alpha_{\| 1 b} \beta_{3}$ ('inside-out' signaling) whereas the inhibitory $\alpha$-subunit down regulates adenylyl cyclase (AC) and therefore cyclic adenosine monophosphate (cAMP) levels which both are pivotal for full and sustained platelet activation and aggregation [18;19]. Finally, fibrinogen-binding to activated integrin $\alpha_{\| 1 b} \beta_{3}$, besides bridging platelets to form aggregates, also contributes to platelet activation and secretion by 'outside-in' signaling [20].

Platelet activation by all these signaling pathways lead to the activation of phospholipase $D$, an enzyme, that catalyses the hydrolysis of phosphatidylcholine into phosphatidic acid (PA) and choline [21]. PA, as well as its metabolites lysoPA and diacylglycerol (DAG) are important second messengers [21]. In the presence of a primary alcohol, such as ethanol or 1-butanol, the alcohol is the preferred substrate, resulting in the generation of the respective phosphatidylalcohols which are metabolically stable and can be quantified for assessing PLD activity [21]. Furthermore, as phosphatidylalcohols have been thought to be inert regarding cellular signaling primary alcohols have been widely applied to interfere with proper PLDmediated PA production to investigate the cellular role(s) of PLD [21;22].

Two isoforms of PLD, PLD1 and PLD2, have been identified. While PLD1 has a low basal activity and is readily activated by PKC and small GTPases of the adenosine diphosphate (ADP)-ribosylation factor (ARF) and Rho family, PLD2 shows a high basal activity and is only 
marginally induced by a variety of activators. In platelets, both PLD isoforms are present [23].

PLD has been reported to be activated by collagen, thrombin, and the TXA $\mathrm{T}_{2}$-mimetic U46619 and, taken together, is thought to be implicated in platelet activation and secretion [24-27]. This was further supported by the analysis of Pld $1^{-\%}$ platelets that identified PLD1 as critical regulator of platelet activity. The lack of PLD1 in platelets induces impaired integrin $\alpha_{\| 1 b} \beta_{3}$ activation and shear dependent thrombus formation leading to protection against arterial thrombosis and ischemic brain infarction [28]. However, the absence of specific inhibitors and mice that are deficient in the PLD isoform PLD2 precluded the analysis of PLD2 function in platelets.

Recently the novel pharmacological PLD-inhibitor FIPI has been developed and characterized [22]. Most intriguingly, it was found that cellular responses applying 1-butanol or FIPI essentially differed, strongly suggesting that the proposed role(s) of PLD need(s) to be re-evaluated. In this study we found that FIPI induced PLD inhibition resulted in enhanced PKC-mediated secretion and aggregation in human platelets. As comparable effects of FIPI were found with mouse wild-type and $P / d 1^{-/}$platelets our findings strongly point to a new role for PLD2 as negative regulator of platelet sensitivity. 


\section{Material and methods}

\subsection{Chemicals and Antibodies}

FIPI (4-Fluoro-N-(2-(4-(5-fluoro-1H-indol-1-yl)piperidin-1-yl)ethyl)benzamide, 5-Fluoro-2indolyl des-clorohalopemide hydrochloride hydrate), apyrase (Grade III, from potatoe), aspirin (acetylsalicylic acid), fura-2/AM (fura 2 acetoxymethylester), bovine thrombin (T4648), and U46619 (9,11-dideoxy-11 $\alpha, 9$-epoxy-methanoprostaglandine (F2 $\alpha)$ were purchased from Sigma. Collagen (type I, from equine tendons) and the luciferin/luciferase reagent including the ATP-standard (CHRONOLUME ${ }^{\circledR}$ ) were from Chrono-Log.ICl192,605 (4-(Z)-6(2-o-Chlorophenyl-4-o-hydroxyphenyl-1,3-dioxan-cis-5-yl)hexenoic acid) and Y27632 (trans-4[(1R)-1-Aminoethyl]- $N$-4-pyridinylcyclohexanecarboxamide dihydrochloride) were from Tocris. AYPGKF-NH ${ }_{2}$ and SFLLRN were custom-synthesized by JPT Peptide Technologies. ReoPro ${ }^{\circledR}$ (abciximab) was from Eli Lilly, and Cangrelor ${ }^{\circledR}$ was a kind gift from the Medicines Company.All other reagents were of analytical grade.

The phospho-MLC2 (Ser19) antibody (\#3675), the phospho-(Ser) PKC Substrate Antibody (\#2261), as well as the HRP-conjugated secondary antibodies (\#7074 and \#7076) were from Cell Signaling Technology; the antibody detecting unmodified pleckstrin was from Abcam (ab17020), and the $\beta$-tubulin antibody (clone AA2) from Upstate/Millipore.

\subsection{Preparation of isolated human platelets}

Heparinized blood $(10 \mathrm{U} / \mathrm{ml}$ ) was obtained from Linköping University Hospital's blood bank. Blood was transferred in a volumetric proportion of 5:1 to acid-citrate-dextrose (ACD: $71 \mathrm{mM}$ citric acid, $85 \mathrm{mM}$ sodium citrate, $111 \mathrm{mM}$ glucose) and centrifuged at $220 \mathrm{~g}$ for $20 \mathrm{~min}$. The platelet-rich plasma (PRP) thus obtained was incubated with $100 \mu \mathrm{M}$ aspirin for $30 \mathrm{~min}$, and platelets were collected by centrifugation at $520 \mathrm{~g}$ for $25 \mathrm{~min}$. Platelet pellets were carefully washed three times with Krebs-Ringer Glucose (KRG) buffer (120 mM NaCl, 4.9 mM KCl, 1.2 $\mathrm{mM} \mathrm{MgSO}$, $1.7 \mathrm{mM} \mathrm{KH}_{2} \mathrm{PO}_{4}, 8.3 \mathrm{mM} \mathrm{Na}_{2} \mathrm{HPO}_{4}, 10 \mathrm{mM}$ glucose; $\mathrm{pH}$ 7.3), and finally resuspended in KRG containing $0.05 \mathrm{U} / \mathrm{ml}$ apyrase. The platelet count was determined using 
an automatic blood cell counter (ABX Micros 60 (ABX Diagnostics, Montpellier, France)) and

was adjusted to a final assay concentration of $2.5 \times 10^{8}$ platelets $/ \mathrm{ml}$. Suspensions were supplemented with $1 \mathrm{mM} \mathrm{CaCl} 230$ min prior to experimentation. All isolation steps were carried out at room temperature (RT).

\subsection{Human platelet aggregation and ATP release}

Measurements were performed at $37^{\circ} \mathrm{C}$ using a Chronolog Dual Channel lumi-aggregometer (Model 560, Chrono-Log, Haverston, PA, USA) with stirring at $800 \mathrm{rpm}$ using a final volume of $0.3 \mathrm{ml}$ platelet suspension. Aggregation is expressed as percentage light transmission compared to KRG alone $(=100 \%)$. Extracellular ATP was assessed applying the luciferin/luciferase bioluminescent assay and calculated using an exogenously added ATP standard.

\subsection{Human platelet $\mathrm{Ca}^{2+}$ mobilization measurements}

Platelets were loaded with fura-2 by incubating PRP with $3 \mu \mathrm{M}$ fura-2/AM for 45 min at RT and subsequently isolated as described above. Platelets were pre-incubated and stimulated as indicated at $37^{\circ} \mathrm{C}$ and fluorescence was recorded using a Hitachi F-7000 spectrofluorometer (Hitachi Ltd., Tokyo, Japan) at $510 \mathrm{~nm}$ with simultaneous excitation at $340 \mathrm{~nm}$ and $380 \mathrm{~nm}$. Cytosolic calcium $\left[\mathrm{Ca}^{2+}\right]_{i}$ is expressed in fluorescence ratio $(340 / 380$ $\mathrm{nm})$.

\subsection{Immuno(Western)blotting}

Stimulation of human platelets were carried out at $37^{\circ} \mathrm{C}$ in a total volume of $200 \mu \mathrm{l}$ in $2 \mathrm{ml}$ round-bottom tubes in a thermoshaker rotating at $900 \mathrm{rpm}$; pre-incubations at $500 \mathrm{rpm}$. Reactions were stopped by the addition of $50 \mu \mathrm{l} 5 \mathrm{x}$ SDS sample buffer, and proteins were denatured at $95^{\circ} \mathrm{C}$ for 5 min. Proteins were separated on $4-12 \%$ NuPAGE ${ }^{\circledR}$ Novex Bis-Tris gels with MOPS running buffer (Invitrogen). To determine apparent molecular protein masses MagicMark ${ }^{\mathrm{TM}}$ XP Western Protein Standard (Invitrogen) was used. Proteins were 
blotted onto Immun-Blot ${ }^{\text {TM }}$ PVDF membranes $(0.2 \mu \mathrm{m})$ (BioRad). For further steps TBS-T (10

$\mathrm{mM}$ Tris- $\mathrm{HCl} \mathrm{pH}$ 8.0, $150 \mathrm{mM} \mathrm{NaCl}, 0.1 \%(\mathrm{w} / \mathrm{v})$ Tween-20) was used. Protein bands were visualized by the use of Immobilon ${ }^{\mathrm{TM}}$ Western Chemiluniescent HRP Substrate solution from Millipore (Billerica), and chemiluminiscence was recorded by a Fuji LAS 1000 system; densitometric analysis was performed with Image Gauge 3.46 software (Fuji Photo Film, Tokyo, Japan).

\subsection{Animals}

Pld mutant mice were described before [69]. $\mathrm{Pld}^{+/}$mice were intercrossed to generate $\mathrm{Pld}^{+/+}$ and $\mathrm{Pld}^{-/}$mice. Ablation of PLD1 was monitored by PCR and immunoblotting, as previously described. Animal studies were performed in accordance with the guidelines for the use of living animals in scientific studies and the German law for the protection of animals and approved by the Regional Council Tübingen (Regierungspräsidium Tübingen).

\subsection{Murine platelet preparation}

Mice were bled form the retro-orbital plexus and murine blood was collected in a tube. Citrate-anticoagulated blood was centrifugated at $1800 \mathrm{rpm}$ for 5 minutes at room temperature. To obtain platelet-rich plasma (PRP) the supernatant was centrifugated at $800 \mathrm{rpm}$ for $6 \mathrm{~min}$. For the preparation of washed platelets PRP was washed twice at $2800 \mathrm{rpm}$ for $5 \mathrm{~min}$ at room temperature and the pellet was resuspended in Tyrode's buffer [136 mM NaCl, $0.4 \mathrm{mM} \mathrm{Na} \mathrm{HPO}_{4}, 2.7 \mathrm{mM} \mathrm{KCl}, 12 \mathrm{mM} \mathrm{NaHCO} 3,0.1 \%$ glucose, $0.35 \%$ bovine serum albumin (BSA), $\mathrm{pH} 7.4$ ] supplemented with prostacyclin $(0.5 \mu \mathrm{M})$ and apyrase $(0.02 \mathrm{U} / \mathrm{mL})$. Before use, platelets were resuspended in the same buffer without prostacyclin ( $\mathrm{pH} 7.4,0.02 \mathrm{U} / \mathrm{mL}$ apyrase) and incubated at $37^{\circ} \mathrm{C}$ for $30 \mathrm{~min}$.

\subsection{Murine platelet aggregometry and ATP-release measurement}

Aggregation experiments were performed with fresh isolated mouse platelets using light transmission aggregometry. Experiments were done with a Chrono Log lumi aggregometer 
(Model 700; Chrono Log Corporation; Havertown, USA) and isolated mouse platelets were

diluted with Tyrodes buffer to a final concentration of $2,5 \times 10^{5}$ platelets. Following calibration PAR-4 activating peptide was added in the indicated concentrations $(25 \mu \mathrm{M}, 50 \mu \mathrm{M}, 75 \mu \mathrm{M}$, $100 \mu \mathrm{M})$ and aggregation was measured for 10 minutes with a stir speed of $1.000 \mathrm{rpm}$ at $37^{\circ} \mathrm{C}$. For FIPI measurements samples were treated 3 minutes prior to measurement with $10 \mu \mathrm{M}$ FIPI or vehicle (DMSO). The extent of aggregation was quantified in $\%$ of light transmission by comparing the deflection of the trace with the calibration mark representing 0 \%. When concomitant ATP-release was determined CHRONOLUME® (Chrono Log Corporation) was added and calibration was done like described in the manufacturer's instruction 2 minutes prior measurement. The data analysis was performed with AGGRO/LINK8 software (Chrono-Log Corporation).

\subsection{PLD activity measurements}

PLD activity was measured in an enzymatically coupled fluorescent in vitro assay (Amplex® Red Phospholipase D Assay Kit, Molecular Probes). In this assay, phosphatidylcholine is hydrolyzed by PLD in the presence of $\mathrm{PI}(4,5) \mathrm{P}_{2}$ to generate $\mathrm{PA}$ and choline, which is then oxidized by choline oxidase to betaine and $\mathrm{H}_{2} \mathrm{O}_{2}$. When horseradish peroxidase is present, $\mathrm{H}_{2} \mathrm{O}_{2}$ oxidizes Amplex red in a 1:1 stoichiometry to generate fluorescent resorufin (7-hydroxy$3 H$-phenoxazin-3-one). This fluorescent assay is able to effectively measure PLD activity in the presence and absence of activators. PLD activity is expressed as a percentage of that obtained with thrombin. In brief, washed platelets were adjusted to a concentration of $1 \mathrm{x}$ $10^{6} / \mu \mathrm{l}$ and activated with different concentrations of PAR-4 activating peptide as indicated at $37^{\circ} \mathrm{C}$ under stirring conditions $(350 \mathrm{rpm})$. After cell lysis, samples $(100 \mu \mathrm{l})$ were mixed with $100 \mu \mathrm{l}$ of the Amplex red reaction buffer (Amplex Red PLD assay kit, Molecular Probes). The PLD activity was determined for each sample by measuring fluorescence activity after a 1hour incubation at $37^{\circ} \mathrm{C}$ in the dark with the GloMax®-Multi detection system (Promega). A standard curve with different concentrations ranging from 0 to $250 \mathrm{mU} / \mathrm{ml}$ was performed using purified PLD from Streptomyces chromofuscus (Sigma-Aldrich). 
1

\subsection{Statistical analysis}

Data analysis was performed using GraphPad Prism 4 software (GraphPad Software Inc., San Diego, CA, USA). Results are presented as mean \pm standard error of the mean (S.E.M.) and statistical significances were calculated as indicated 


\section{Results}

PLD is a signaling enzyme that generates the second messenger PA implicated in many cellular processes like adhesion, integrin activation [28], cell spreading [29], chemotaxis [22] and Ras activation [30]. PA production by PLD is abrogated by primary alcohol derivates like ethanol or 1-butanol. Furthermore, several other inhibitors of PLD activity have been investigated like ceramide [31], neomycin [32] and natural products [33]. However, these compounds sequester the essential co-factor of PLD PIP 2 , work indirectly to inhibit PLD or display many other effects on signaling pathways making their use more complicated and the interpretation of data difficult. In order to validate PLD function in human and murine platelets the present study makes use of the analog 5-fluoro-2-indolyl des-chloro-halopemide (FIPI) that has been shown to potently inhibit PLD1 and PLD2 [22;34].

\subsection{PLD inhibition by FIPI enhances platelet dense granule secretion and aggregation in human platelets}

FIPI was reported to inhibit both PLD1 and PLD2 in a dose-dependent manner, with 50\% loss of activity observed at approximately $25 \mathrm{nM}$ [22]. Thus, FIPI is a potent, concentrationdependent PLD2 inhibitor that inhibits PLD1 equally well under in vitro assay conditions [22;34]. To elucidate the impact of FIPI on platelet function we tested the influence of the inhibitor on human platelet dense granule secretion and aggregation and performed measurements using a Chronolog Dual Channel lumi-aggregometer. Aggregation was expressed as percentage light transmission and extracellular ATP as a marker for dense granule secretion was assessed by a luciferin/luciferase bioluminescent assay. Because FIPI was not tested in platelets before, we performed dose-response curves and found concentration-dependent effects of FIPI on dense granule secretion and aggregation of human platelets (fig. S1). Furthermore, activation of human platelets with sub-/threshold concentrations of thrombin (Fig. 1A) led to enhanced ATP release compared to controls as shown in figure 1 . In response to thrombin, aggregation upon treatment with FIPI was likewise enhanced (fig. 1B). With reference to thrombin-induced platelet activation, amplifying 
effects of FIPI on ATP release and aggregation were observed when platelets were

challenged with sub-/threshold concentrations of the PAR-1 activating peptide SFLLRN, which activates the thrombin receptor PAR-1 in human platelets (PAR-1) and the PAR-4 activating peptide AYPGKF, which activates the thrombin receptor PAR-4 in human platelets (PAR-4) (fig. 1C-F).

\subsection{Discrepancy between FIPI- and alcohol-mediated effects on $\mathrm{Ca}^{2+}$ mobilization, platelet aggregation and secretion}

The key step for different processes of platelet activation including granule release and aggregation is the increase in cytosolic $\mathrm{Ca}^{2+}$ concentration $\left[\mathrm{Ca}^{2+}\right]_{\mathrm{i}}$. Therefore, spectrofluorimetric measurements were employed to investigate the effect of FIPI and thus of PLD inhibition on the increase of cytosolic $\mathrm{Ca}^{2+}$ activity. In the presence of extracellular $\mathrm{Ca}^{2+}$ agonist-induced $\mathrm{Ca}^{2+}$ influx from the extracellular compartment was indistinguishable between FIPI-treated human platelets and controls in response to sub maximal doses of PAR-1 activating peptide (Fig. 2A). In line with these results, the increase of cytosolic $\mathrm{Ca}^{2+}$ activity triggered by different concentrations of the PAR- 4 activating peptide was similar in control and FIPI-treated human platelets (Fig. 2C).

PLD mediated production of PA is inhibited by primary alcohols due to the generation of phosphatidylalcohol. Thus we compared the effect of FIPI and primary alcohols on cellular processes such as $\mathrm{Ca}^{2+}$ mobilization by performing additional spectrofluorimetric measurements in the presence of ethanol and 1-butanol. As shown in Fig. 2A-B, 1-butanol alone elicited minor $\mathrm{Ca}^{2+}$ mobilization and significantly reduced the response to PAR-1 stimulation in human platelets confirming recent concerns about additional effects of primary alcohols on cellular function beside inhibition of PA production. In contrast, ethanol did not influence $\mathrm{Ca}^{2+}$ mobilization in human platelets suggesting distinct side effects of primary alcohols on cell physiology.

Furthermore, the determination of ATP release and aggregation of human platelets in response to various concentrations of PAR-1 and PAR- 4 activating peptides revealed distinct 
inhibitory effects of primary alcohols compared to FIPI (fig. S2). At sub-/threshold

concentrations of PAR-1 and PAR-4 activating peptides, i.e. 5 and $50 \mu \mathrm{M}$, respectively, we observed that FIPI significantly amplified ATP release and consequently platelet aggregation, whereas neither ethanol nor 1-butanol had any effect. At $10 \mu \mathrm{M}$ PAR-1 activating peptide FIPI likewise significantly enhanced ATP release, but not platelet aggregation which was already almost fully induced at this peptide concentration. In contrast, ethanol significantly reduced ATP release and platelet aggregation provoked by $10 \mu \mathrm{M}$ PAR-1 activating peptide, whereas 1-butanol completely inhibited platelet aggregation (fig. S2B). Although we observed comparable effects of FIPI and ethanol on ATP release and aggregation when platelets were stimulated with $100 \mu \mathrm{M}$ PAR-4 activating peptide, pretreatment with 1-butanol under these conditions, however, did only marginally affect platelet aggregation (fig. S2D).

We have not been able to measure ATP release following 1-butanol treatment with the luciferin/luciferase assay, most likely due to a disruption of the reagent(s); as the signal normally evoked by the externally added ATP standard was almost completely abrogated (data not shown). However, this observation further suggests that 1-butanol causes PLDindependent effects

Taken together, these results provide strong evidence that the FIPI-mediated inhibition of PLD enhances platelet dense granule secretion and aggregation but has no influence on $\mathrm{Ca}^{2+}$ mobilization, whereas ethanol and 1-butanol display distinct inhibitory effects on ATP release, platelet aggregation and $\mathrm{Ca}^{2+}$ mobilization depending on the applied stimulus.

\subsection{Proper ROCK signaling is a prerequisite for FIPI-induced effects on dense granule secretion and aggregation}

Platelet adhesion and aggregation induces thrombus formation mediated mainly by the actinbased reorganization of the platelet cytoskeleton accompanied by fibrinogen binding to activated integrin $\alpha_{\| 1} \beta_{3}$ [20]. Small GTPases of the Rho family, namely RhoA, Cdc42 and Rac1, are key regulators of signaling pathways that regulate the reorganization of the cytoskeleton [35]. Furthermore, they play an important role in platelet secretion and 
activation of Phospholipase $\mathrm{C} \gamma 2$ [36;37]. To analyze if FIPI-mediated effects on platelet degranulation and aggregation implies RhoA and its downstream effector Rho-associated coiled-coil forming protein serine/threonine kinase (ROCK) we performed experiments using the ROCK inhibitor Y27632. As shown in figure 3A-B, dense granule secretion and aggregation in response to low and intermediate (50 and $100 \mu \mathrm{M})$ but not high concentrations (200 and $400 \mu \mathrm{M})$ of PAR-4 activating peptide was reduced by the ROCK inhibitor Y27632 suggesting that proper Rho kinase signaling is a prerequisite for FIPIinduced effects on secretion and aggregation in human platelets. However, the phosphorylation of MLC was not altered by FIPI, suggesting that the PLD inhibitor does not affect the assembly of actomyosin filaments (Fig. 3C).

\subsection{FIPI Inhibition of PLD amplifies the first wave of dense granule secretion upon $T X A_{2}$ induced activation of platelets}

Activation of human platelets with sub-/threshold concentrations of collagen led to enhanced ATP release compared to controls (fig. S3). In contrast to the observed significant enhancement of ATP release with $2.5 \mu \mathrm{g} / \mathrm{ml}$ collagen, the effects on platelet aggregation were not that distinct (fig. S3B). In two out of four donors $2.5 \mu \mathrm{g} / \mathrm{ml}$ collagen alone induced aggregation of $25.6 \pm 0.3 \%$ which was enhanced to $79.9 \pm 1.2 \%$ upon pretreatment of cells with FIPI. In the other two donors $2.5 \mu \mathrm{g} / \mathrm{ml}$ collagen alone already provoked platelet aggregation of $90.9 \pm 3.0 \%$, and in the presence of FIPI up to $91.2 \pm 3.6 \%$.

However, and more important, when we interrupted $\mathrm{TXA}_{2}$ signaling by either inhibiting its synthesis with aspirin or by blocking TP $\alpha$ activation with the receptor-antagonist ICI192,605 (fig. S3A-B) we observed nearly full abrogation of ATP release and platelet aggregation evoked by either 2.5 or $5 \mu \mathrm{g} / \mathrm{ml}$ collagen, respectively, clearly demonstrating that the enhancing effects of FIPI on collagen-induced platelet activation almost completely depend on intermediate $\mathrm{TXA}_{2}$ signaling.

Platelet secretion and aggregation mediated by the platelet agonist thromboxane A2 $\left(\mathrm{TXA}_{2}\right)$ are crucial for thrombus formation [38;39]. Characteristically, upon platelet activation with the 
$\mathrm{TXA}_{2}$ analogue U46619 two distinct waves of platelet secretion can be observed that

precede a biphasic course of platelet aggregation. Interestingly, whereas the first wave of dense granule secretion is directly induced by the primary stimulatory impact and partially by released $A D P$ and $P_{2} Y_{12}$ receptor signaling, the second wave of secretion strictly relies on either $P_{2} Y_{12}$ receptor or integrin $\alpha_{\| 1 b} \beta_{3}$ signaling [39]. To study the physiological consequences of FIPI treatment on these biphasic platelet responses, human platelets were activated with different concentrations of $\mathrm{TXA}_{2}$ and platelet aggregation and dense granule secretion were monitored in a lumi-aggregometer in real time. At sub-/threshold concentrations of $\mathrm{TXA}_{2}(0.5$ $\mu \mathrm{M})$ that did not induce secretion or aggregation of control platelets the addition of FIPI induced the characteristic two waves of secretion and thus platelet aggregation (Fig. 4A-B). In addition, these characteristic two waves of secretion and platelet aggregation were observed in both FIPI-treated and control platelets after stimulation with $1 \mu \mathrm{M} \mathrm{TXA}_{2}$. As shown in figure $4 \mathrm{~A}$, the first wave of platelet secretion was observed promptly after addition of $1 \mu \mathrm{M} \mathrm{TXA}$ followed by the second wave of platelet secretion. Pre-treatment of human platelets with FIPI enhanced the first wave of platelet secretion compared to control.

To investigate the influence of FIPI on $\mathrm{TXA}_{2}$-induced platelet secretion and aggregation in further detail, we assessed the impact of the ADP-activated $G_{i}$ pathway and integrin $\alpha_{\| 1} \beta_{3}$ outside-in signaling that were both known to be essential for the second wave of secretion and irreversible platelet aggregation. Using the $\mathrm{P}_{2} \mathrm{Y}_{12}$ inhibitor Cangrelor ${ }^{\circledR} \mathrm{FIPI}$ treated platelets showed a markedly but not significantly reduced first wave of platelet secretion after stimulation with $1 \mu \mathrm{M}$ TXA 2 while the second wave of secretion was completely abolished (fig. 4A). In contrast, while the first wave of secretion was unaltered, the second wave was similarly abrogated in the presence of the monoclonal antibody ReoPro® that binds to integrin $\alpha_{11 b} \beta_{3}$ to inhibit fibrinogen binding and thus platelet aggregation. Consequently, platelet aggregation was strongly reduced in platelets pre-treated with Cangrelor ${ }^{\circledR}$ and FIPI or ReoPro® and FIPI compared to controls and FIPI treated platelets (fig. 4B).

Together, these results indicate that PLD inhibition by FIPI amplifies the first wave of dense granule secretion upon $\mathrm{TXA}_{2}$-mediated activation of human platelets. 


\subsection{Phosphorylation of the protein kinase $C$ substrate pleckstrin is enhanced upon treatment with the PLD inhibitor FIPI}

Protein kinase $\mathrm{C}$ is a major regulator of platelet granule secretion, integrin activation, aggregation and spreading [40]. Following agonist-induced platelet activation, PKC induces phosphorylation of its substrate pleckstrin that is translocated to the plasma membrane to exert downstream effects on platelet secretion, aggregation and exocytosis [41]. To analyze if FIPI-induced increase in platelet secretion relies on PKC and its substrate pleckstrin, we investigated PKC substrate serine phosphorylation provoked by 50 (fig. $5 \mathrm{~A}-\mathrm{B}$ ) and $100 \mu \mathrm{M}$ (fig. 5C-D) PAR-4 activating peptide, respectively. At threshold concentrations of PAR-4 activating peptide $(50 \mu \mathrm{M})$, FIPI-treated platelets responded with a significant increase in serine phosphorylation of pleckstrin in a time dependent manner (fig. 5A-B). Likewise, FIPI induced enhanced phosphorylation of pleckstrin after stimulation with $100 \mu \mathrm{M}$ PAR-4 activating peptide (fig. 5C-D). Notably, in the presence of FIPI $50 \mu \mathrm{M}$ PAR-4 activating peptide provoked pleckstrin phosphorylation after 60 and 120 seconds of stimulation (fig. 5AB) to an extent comparable to that induced by $100 \mu \mathrm{M}$ PAR-4 activating peptide alone (fig. 5C-D). These data suggest that enhanced platelet secretion upon FIPI treatment of human platelets relies on an increase in PKC activity.

\subsection{PLD inhibition by FIPI augments dense granule secretion and aggregation in murine wild-type and PId1 ${ }^{-/}$platelets}

We next investigated the influence of FIPI and thus PLD inhibition on dense granule secretion and aggregation of mouse platelets. Comparable to the results obtained with human platelets (fig. 1E-F), we observed enhanced effects of FIPI on dense granule secretion and aggregation of platelets from wild-type mice stimulated with increasing concentrations of PAR-4 activating peptide (fig. 6A-B). 
PLD has been shown to be involved in signal transduction pathways leading to platelet activation and thrombus formation [24-26;28]. In Pld1\% mice, platelet activation and thrombus formation was strongly impaired while degranulation and aggregation in response to different agonists was unaffected by PLD1 deficiency [28]. To investigate the enhanced effects on platelet aggregation and secretion induced by FIPI in further detail we analyzed dense granule secretion and aggregation of $P l d 1^{-/}$platelets to test the potential role of PLD2 in platelet function. As shown in figure 6, ATP release (fig. 6C) and aggregation (fig. 6D) were significantly enhanced in Pld $1^{-/}$platelets pretreated with FIPI compared to $\mathrm{Pld} 1^{-/}$platelets pretreated with DMSO (control). These results indicate that the inhibition of the basal highly active PLD2 may account for the observed effects on aggregation and secretion in human and mouse platelets.

This was further supported by a PLD assay (fig. S4) that measures choline production as marker for PLD activity. This PLD assay was found to be a useful and reliable tool for PLD research because comparable results were obtained from the "classical" transphosphatidylation assay where the formation of $\left[{ }^{3} \mathrm{H}\right]$ phosphatidylbutanol was measured making the use of alcohols unnecessary [28]. In activated platelets, PLD activity was strongly reduced in $\mathrm{Pld}^{-/}$platelets pre-treated with FIPI compared to wild-type platelets, wild-type platelets pre-treated with FIPI and $\mathrm{Pld} 1^{-/}$platelets, respectively. Moreover, PLD activity was abrogated in FIPI treated Pld1\% platelets under resting conditions while this basal activity was comparable between wild-type and Pld1\% platelets (fig. S4). This data also provides evidence that the remaining PLD activity in $P / d 1^{-/}$platelets results from basal activity of the PLD2 isoform and does not represent the assay background. 


\section{Discussion}

The present study unravels a novel putative role for PLD as an endogenous negative regulator of $\mathrm{G}_{\alpha} / \mathrm{PKC}$-mediated dense granule secretion and aggregation and thus for platelet activation. Using the pharmacological PLD-inhibitor FIPI we found enhanced dense granule secretion and aggregation in human and mouse wild-type and Pld1\% platelets following stimulation with sub-/threshold concentrations of agonists which induce $G \alpha_{12 / 13}$ and $G \alpha_{q}$ signaling in platelets. While FIPI has no effect on $\mathrm{Ca}^{2+}$ mobilization and MLC phosphorylation, the effect of FIPI on aggregation and secretion was supported by proper Rho-kinase signaling. Furthermore, FIPI prominently amplified phosphorylation of the PKC substrate pleckstrin known to be associated with granule secretion.

In former studies, primary alcohols have been used to identify PLD/PA driven cellular processes. The presence of 1-butanol in cell culture medium has been shown to inhibit a variety of cell functions [22;42]. Primary alcohols are preferentially used by PLDs to generate phosphatidyl (Ptd)-alcohol instead of PA, thereby abrogating signal transduction processes mediated by PA. However, despite the commonly used primary alcohols over the last decades to block PLD function, it is not clear to date, whether they fully block PA generation and whether they have other effects on cell morphology or function beyond inhibition of PA generation [43;44]. In the present study we compared effects of the PLD-inhibitor FIPI with primary alcohol derivates. In contrast to FIPI, ethanol and especially 1-butanol displayed distinct inhibitory effects on PAR-1 and PAR-4 activating peptide-induced $\mathrm{Ca}^{2+}$ mobilization, dense granule secretion and aggregation of human platelets indicating that prior studies that rely on PLD inhibition by primary alcohols must be re-evaluated. In the nineties Coorssen and Haslam proposed that PLD is important for human platelet secretion by using ethanol to block PLD mediated effects on degranulation [45]. In a recent study it was shown that 1butanol abrogated platelet aggregation by PAR-1 but not PAR-4 activating peptide [46]. In the present study we observed similar effects induced by primary alcohols but obtained completely opposite results when FIPI was used to determine platelet secretion and 
aggregation confirming the unspecific and PLD-unrelated effects of the (formerly) used

alcohols.

Different approaches to inhibit PLD activity revealed that PLD is involved in exocytosis [47]. These finding was supported by studies where PLD was inhibited by FIPI, but a limiting aspect of this inhibitor is the dual effect on both PLD isoforms, PLD1 and PLD2, where e.g. secretion can by facilitated by PLD1 while this effect is opposed by PLD2 [22]. In the present study, $\mathrm{Ca}^{2+}$ influx from the extracellular compartment was unaffected by FIPI. These results indicate that either PLD inhibition by FIPI has no effect on $\mathrm{Ca}^{2+}$ mobilization or that both PLD isoforms effect $\mathrm{Ca}^{2+}$ homeostasis in opposed manner thus concealing isoform-specific effects on $\mathrm{Ca}^{2+}$ mobilization. Furthermore, MLC phosphorylation was not altered upon treatment with FIPI. In contrast, inhibition of ROCK demonstrated that proper Rho-kinase signaling is important for effects on platelet activation mediated by FIPI. Former studies identified PLD as a mediator of cytoskeleton reorganization and proposed PLD2 as master regulator that controls Rho function in neutrophils and other cells [48;49]. Down-regulation of PLD2 was shown to decrease PA production leading to myosin light chain phosphatase (MLCP) release, dephosphorylation of MLC and thus actomyosin disassembly in chinese hamster ovarian (CHO) cells [29]. In addition, $\mathrm{PA}$ regulates $\mathrm{PI}(4) \mathrm{P} 5$ kinase, which is required for $\mathrm{PIP}_{2}$ synthesis known to play an important role in membrane ruffling, vesicle trafficking and stress fibre formation [50]. Moreover, Rho-kinase signaling also implies LIM kinase (LIMK) induced phosphorylation of members of the ADF/cofilin family of actin binding and filament severing proteins that may also involve PLD activity [51]. In a recent study by Han and colleagues it has been shown that Cofilin directly and specifically interacts with PLD1 and upon phosphorylation by LIMK, stimulates PLD1 activity [52].

In the present study we show that FIPI enhanced dense granule secretion in human platelets in response to sub-/threshold concentrations of thrombin, PAR-1 and PAR-4 activating peptide as well as U46619. A role for PLD in secretion and secretory vesicle formation in different cell types was already described several years before [45;53]. PLD was proposed to be important in ARF-dependent exocytosis [54;55] and secretion of neuroendocrine cells 
[31], adipocytes [56], pancreatic B cells [57], mast cells [58] and platelets [45]. Moreover, a

recent study from Qin and colleagues provide evidence that PLD2 mediates aldosterone secretion in adrenal glomerulosa cells while PLD1 overexpression had only little effect on aldosterone secretion [59]. PKC is known as major regulator of platelet activity [40]. PKC activity is essential for granule seretion as shown with PKC inhibitors that prevent granule secretion [60;61] and aggregation [62;63]. Pleckstrin is the major substrate for PKC in platelets and macrophages [64]. Mice lacking pleckstrin display marked defects in exocytosis of granula, integrin activation and aggregation in response to PKC stimulation [41]. Here we show, that FIPI induced inhibition of PLD led to amplified phosphorylation of pleckstrin indicating that PLD plays a putative role as an endogenous negative regulator of PKCmediated dense granule secretion and aggregation. Further, PKC $\alpha$ has been reported to phosphorylate PLD2 [65] leading to the inactivation of the enzyme suggesting a feedback loop for PLD/PKC mediated activation and inactivation.

Former studies demonstrated that PLD1 inhibition/deficiency in platelets led to reduced integrin activation and thrombus formation while degranulation and aggregation was unaffected by the lack of PLD1[28]. However, to discriminate between PLD1- and PLD2mediated effects of FIPI on platelet activation we analyzed platelet secretion and aggregation in $\mathrm{Pld}^{-}$platelets. FIPI treatment of $\mathrm{Pld}^{-\kappa}$ platelets led to enhanced ATP release and aggregation compared to $\mathrm{Pld} 1^{-}$platelets indicating that basal highly active PLD2 may account for the observed effects on aggregation and secretion in human and murine platelets. This hypothesis was further confirmed by measuring PLD activity that was significantly reduced in $\mathrm{Pld} 1^{\%}$ platelets pre-treated with FIPI. In a recent study it was already shown that basal PLD activity was comparable between wild-type and $P I d 1^{-1 /}$ platelets. Thus, the authors suggested that basal PLD activity is derived from activity of the PLD2 isoform in platelets, a hypothesis, that is supported by the present study [28]. Upon platelet activation PLD activity was strongly reduced indicating that PLD1 is responsible for the bulk of inducible PLD activity in activated murine platelets [28]. Former studies suggested that PLD2 displays high basal activity and is only moderately activated by classical PLD1 activators such as 
PKC and small G-proteins of the ARF and Rho family [66;67] although both isoforms require

$\mathrm{PIP}_{2}$ as cofactor [68].

According to our findings and in line with current knowledge, we propose that FIPI-induced inhibition of the basal highly active PLD2 is responsible for enhanced platelet activation pointing to a novel role for PLD2 as endogenous negative regulator of dense granule secretion and aggregation and thus for platelet activation.

In the last years, PLD has been shown to play a role in several tumor types. PLD1 and PLD2 expression and activity are up regulated in different types of cancer therefore the inhibition of PLD was discussed to be a promising tool in cancer therapy [43]. In addition, PLD also plays a role in the context of immune responses [43] suggesting that PLD may also be a target for the treatment of disease with inflammatory components. FIPI pharmacokinetics show promising results in terms of half-life and bioavailability in vivo that renders FIPI an attractive substance for metastasis studies in mice [34]. However, according to the current study it has to be critically evaluated if the inhibition of PLD might be a useful strategy for therapy because one might expect that in vivo application of FIPI may lead to increased risk of pathological thrombus formation. Further studies are required to examine in vivo application of FIPI in animal studies and to understand PLD mediated cellular function and regulation and their impact on disease. 


\section{Conclusions}

5.1 The PLD inhibitor FIPI enhances dense granule secretion and aggregation of human platelets.

5.2 FIPI has no effect on cytosolic $\mathrm{Ca}^{2+}$ activity but needs proper Rho kinase signaling to mediate FIPI-induced effects on platelet activation.

5.3 The phosphorylation of the PKC substrate pleckstrin was prominently enhanced upon FIPI treatment suggesting that FIPI affects PKC-mediated secretion and aggregation

5.4 Similar effects of FIPI were observed in platelets from mouse wild-type and $\mathrm{Pld} 1 \%$ mice pointing to a new role for PLD2 as negative regulator of platelet sensitivity. 


\section{Supplementary data}

Fig. S1. Concentration-dependent effects of FIPI on dense granule secretion and aggregation of aspirinated human platelets stimulated with $50 \mu \mathrm{M}$ PAR-4 activating peptide.

Fig. S2. Primary alcohol derivates display distinct inhibitory effects on platelet dense granule secretion and aggregation compared to FIPI.

Fig. S3. FIPI enhances human platelet dense granule secretion and aggregation after stimulation with collagen.

Fig. S4. PLD activity is strongly reduced in FIPI-treated wild-type and PId $1^{-\%}$ platelets.

\section{Acknowledgements}

We thank Christina Flaum for excellent technical assistance. This study was supported by the Swedish Research Council (project number K2010-65X-15060-07-3) and by the Medical Faculty of the University of Linköping through Forskningsoch Forskarutbildningsnämnden (FUN), as well as in part by the Tuebingen Investigative Platelet Consortium (TUEPIC) and the Deutsche Forschungsgemeinschaft (Transregio-SFB-19).

\section{Authorship}

Contributions: M.E. and K.F. performed experiments, analyzed data, designed research, and wrote the manuscript; M.G., H.K., P.M., O.B., and H.T. performed experiments and analyzed data; G.P., F.L., M.G. and T.L. analyzed data and wrote the manuscript.

9. Conflict-of-interest disclosure: The authors declare no competing financial interests. 


\section{Figure legends}

Fig. 1. FIPI enhances platelet dense granule secretion and aggregation in response to thrombin, PAR1 and PAR-4 activating peptide. (A) Human platelets were activated with increasing concentrations of thrombin at $37^{\circ} \mathrm{C}$ and extracellular ATP was assessed applying the luciferin/luciferase bioluminescent assay and calculated using an ATP standard. (B) Platelet aggregation was expressed as percentage light transmission compared to $\mathrm{KRG}$ alone $(=100 \%) \cdot(C+E)$ ATP release and $(D+F)$ aggregation of human platelets in response to different concentrations of PAR1 and PAR-4 activating peptide was assessed in the same way. The results shown are representative for 7 individual experiments. Bar graphs depict mean values \pm S.E.M. ${ }^{*} \mathrm{P}<0.05,{ }^{* *} \mathrm{P}<0.01,{ }^{* \star *} \mathrm{P}<0.001, \mathrm{~ns}=$ not significant.

Fig. 2. FIPI has no effect on $\mathrm{Ca}^{2+}$ mobilization while primary alcohol derivates displayed distinct inhibitory effects on $\mathrm{Ca}^{2+}$ homeostasis. (A) Representative tracings of Fura-2 fluorescence reflecting cytosolic $\mathrm{Ca}^{2+}$ concentration $\left[\mathrm{Ca}^{2+}\right]_{i}$ of washed human platelets pretreated with vehicle, the PLD inhibitor FIPI $(10 \mu \mathrm{M}), 0.05 \%$ ethanol and $0.05 \% 1$-butanol, respectively prior to and following stimulation with $10 \mu \mathrm{M}$ PAR-1 activating peptide in the presence of $1 \mathrm{mM}$ extracellular $\mathrm{Ca}^{2+}$. (B) Histogram of maximal increase in cytoplasmic $\mathrm{Ca}^{2+}$ of human platelets pretreated as indicated prior to stimulation with PAR-1 peptide. Results are given as means \pm S.E.M. (C) Human platelets were pre-treated with FIPI followed by activation with PAR-4 activating peptide in the presence of $1 \mathrm{mM} \mathrm{Ca}^{2+}$ and maximal increase in cytoplasmic $\mathrm{Ca}^{2+}$ was determined. ( $\mathrm{n}=4$ per group). ${ }^{*} \mathrm{P}<0.05, \mathrm{~ns}=$ not significant.

Fig. 3. Proper Rho kinase signaling is a prerequisite for FIPI induced effects on platelet aggregation and secretion. (A) Washed human platelets were incubated with vehicle or 10 $\mu \mathrm{M}$ FIPI for $2.5 \mathrm{~min}$ followed by buffer or $10 \mu \mathrm{M}$ Y27632 for another $2.5 \mathrm{~min}$, respectively and activated with different concentrations of PAR-4 activating peptide at $37^{\circ} \mathrm{C}$ to assess extracellular ATP and (B) platelet aggregation. (C) In response to PAR-4 activating peptide phosphorylation of MLC (Ser19) is not altered upon FIPI treatment. Washed platelets were 
activated for indicated time points with 50 and $100 \mu \mathrm{M}$ PAR-4 activating peptide under

stirring conditions. Samples were analysed by SDS/PAGE, blots were probed with antibodies against phosphorylated MLC. B-Tubulin was used as loading control. The presented blot shown is representative for four individual experiments. Bar graphs depict mean values \pm S.E.M. of densitometric analysis performed with Image Gauge 3.46 software, ns = not significant.

Fig. 4. FIPI amplifies the first wave of dense granule secretion upon U46619-mediated activation of human platelets. Washed human platelets were resuspended with Tyrode's buffer to a final volume of $0.3 \mathrm{ml}$ platelet suspension and pre-incubated at $37^{\circ} \mathrm{C}$ under stirring conditions with vehicle or FIPI for $2.5 \mathrm{~min}$, followed by $10 \mu \mathrm{M}$ Cangrelor® or $50 \mathrm{ng} / \mathrm{ml}$ ReoPro® for additional $2.5 \mathrm{~min}$. Platelets were exposed to $1 \mu \mathrm{M}$ U46619 at indicated concentrations in a platelet lumi-aggregometer and (A) ATP release and (B) platelet aggregation were recorded in real time. Bar graphs depict mean values \pm S.E.M. of both $n=$ 5 individual experiments.

Fig. 5. Effects of FIPI on PAR-4 activating peptide induced phosphorylation of the PKC substrate pleckstrin. Washed human platelets were pre-incubated with vehicle or FIPI and exposed to (A-B) $50 \mu \mathrm{M}$ and (C-D) $100 \mu \mathrm{M}$ PAR-4 activating peptide as indicated at $37^{\circ} \mathrm{C}$ under stirring conditions. Samples were analysed by SDS/PAGE and probed with antibodies recognizing serine-phosphorylated PKC substrate pleckstrin or unmodified pleckstrin. The results shown are representative for four individual experiments. $(B, D)$ Bar graphs depict mean values \pm S.E.M. of densitometric analysis performed with Image Gauge 3.46 software. ${ }^{*} \mathrm{P}<0.05,{ }^{* *} \mathrm{P}<0.01, \mathrm{~ns}=$ not significant.

Fig. 6. Murine wild-type and $\mathrm{Pld} 1^{-/}$platelets responded with enhanced platelet aggregation and granule secretion after FIPI treatment. Isolated mouse platelets were diluted with Tyrode's buffer to a final concentration of $2,5 \times 10^{5}$ platelets and stimulated with PAR-4 
activating peptide as indicated. (A) ATP-release of wild-type platelets pre-incubated with vehicle or FIPI was determined using CHRONOLUME®. (B) The extent of aggregation of wild-type platelets was quantified in \% of light transmission by comparing the deflection of the trace with the calibration mark representing $0 \%$. (C) ATP-release of $P / d 1^{-/-}$platelets preincubated with vehicle or FIPI was determined as described in (A). (D) Pld1/ platelets preincubated with vehicle or FIPI were exposed to different concentrations of PAR-4 activating peptide and aggregation was assessed as described in (B). Data was shown as mean values \pm S.E.M ( $n \geq 6$ mice per group). ${ }^{*} P<0.05,{ }^{* *} P<0.01, n s=$ not significant. 


\section{References}

[1] Z. M. Ruggeri, Platelets in atherothrombosis. Nat. Med. 8 (2002) 1227-1234.

[2] Z. M. Ruggeri, G. L. Mendolicchio, Adhesion mechanisms in platelet function. Circ. Res. 100 (2007) 1673-1685.

[3] M. Gawaz, Role of platelets in coronary thrombosis and reperfusion of ischemic myocardium. Cardiovasc. Res. 61 (2004) 498-511.

[4] D. Varga-Szabo, I. Pleines, B. Nieswandt, Cell adhesion mechanisms in platelets. Arterioscler Thromb. Vasc. Biol. 28 (2008) 403-412.

[5] B. Savage, F. Almus-Jacobs, Z. M.Ruggeri, Specific synergy of multiple substrate-receptor interactions in platelet thrombus formation under flow. Cell 94 (1998) 657-666.

[6] B. Nieswandt, S. P. Watson, Platelet-collagen interaction: is GPVI the central receptor? Blood 102 (2003) 449-461.

[7] M. L., Kahn, M. Nakanishi-Matsui, M. J., Shapiro, H. Ishihara, S. R. Coughlin, Proteaseactivated receptors 1 and 4 mediate activation of human platelets by thrombin. J. Clin. Invest. 103 (1999) 879-887.

[8] S. Offermanns, Activation of platelet function through G protein-coupled receptors. Circ. Res. 99 (2006) 1293-1304.

[9] M. J. Shapiro, E. J.Weiss, T. R. Faruqi, S. R. Coughlin, Protease-activated receptors 1 and 4 are shut off with distinct kinetics after activation by thrombin. J. Biol. Chem. 275 (2000) 2521625221.

[10] M. Bauer, M. Retzer, J. I. Wilde, P. Maschberger, M. Essler, M. Aepfelbacher, S. P.Watson, W. Siess, Dichotomous regulation of myosin phosphorylation and shape change by Rhokinase and calcium in intact human platelets. Blood 94 (1999) 1665-1672.

[11] B. Z. S. Paul, J. L. Daniel, S. P. Kunapuli, Platelet shape change is mediated by both calciumdependent and -independent signaling pathways - Role of p160 Rho-associated coiled-coilcontaining protein kinase in platelet shape change. J. Biol. Chem. 274 (1999) 28293-28300.

[12] S. Offermanns, C. F. Toombs, Y. H. Hu, M. I. Simon, Defective platelet activation in G alpha(q)-deficient mice. Nature 389 (1997) 183-186. 
[13] M. J. Berridge, M. D.Bootman, H. L.Roderick, Calcium signalling: Dynamics, homeostasis and remodelling. Nat. Rev. Mol. Cell Biol. 4 (2003) 517-529.

[14] S. Feske, Calcium signalling in lymphocyte activation and disease. Nat. Rev. Immunol. 7 (2007) 690-702.

[15] A. Habib, G. A. FitzGerald, J. Maclouf, Phosphorylation of the thromboxane receptor alpha, the predominant isoform expressed in human platelets. J. Biol. Chem. 274 (1999) 2645-2651.

[16] S. Offermanns, K. L. Laugwitz, K. Spicher, G. Schultz, G-Proteins of the G(12) Family Are Activated Via Thromboxane A(2) and Thrombin Receptors in Human Platelets. Proc. Natl. Acad. Sci. U.S.A. 91 (1994) 504-508.

[17] B. T. Atkinson, M. J. Stafford, C. J. Pears, S. P.Watson, Signalling events underlying platelet aggregation induced by the glycoprotein VI agonist convulxin. Eur. J. Biochem. 268 (2001) $5242-5248$.

[18] C. Gachet, Identification, characterization, and inhibition of the platelet ADP receptors. Int. J. Hematol. 74 (2001) 375-381.

[19] P. Ohlmann, K. L. Laugwitz, B. Nurnberg, K. Spicher, G. Schultz, J. P. Cazenave, C. Gachet, The human platelet ADP receptor activates G(i2) proteins. Biochem. J. 312 (1995) 775-779.

[20] B. Nieswandt, D. Varga-Szabo, M. Elvers, Integrins in platelet activation. J. Thromb. Haemost. 7 (2009) 206-209.

[21] M. McDermott, M. J. Wakelam, A. J. Morris, Phospholipase D. Biochem.Cell Biol. 82 (2004) 225-253.

[22] W. Su, O. Yeku, S. Olepu, A. Genna, J. S. Park, H. M. Ren, G. Du, M. H. Gelb, A. J. Morris, M. A. Frohman, 5-Fluoro-2-indolyl des-chlorohalopemide (FIPI), a Phospholipase D Pharmacological Inhibitor That Alters Cell Spreading and Inhibits Chemotaxis. Mol. Pharmacol. 75 (2009) 437-446.

[23] M. Vorland, H. Holmsen, Phospholipase D in human platelets: Presence of isoenzymes and participation of autocrine stimulation during thrombin activation. Platelets 19 (2008) 211-224.

[24] E. A. Martinson, S. Scheible, P. Presek, Inhibition of Phospholipase-D of Human Platelets by Protein-Tyrosine Kinase Inhibitors. Cell. Mol. Biol. 40 (1994) 627-634. 
[25] E. A. Martinson, S. Scheible, A. Greinacher, P. Presek, Platelet Phospholipase-D Is Activated by Protein-Kinase-C Via An Integrin Alpha(lib)Beta(3)-Independent Mechanism. Biochem. J. 310 (1995) 623-628.

[26] E. A. Martinson, S. Scheible, A. Marx-Grunwitz, P. Presek, Secreted ADP plays a central role in thrombin-induced phospholipase D activation in human platelets. Thromb. Haemost. 80 (1998) $976-981$.

[27] J. R. Nofer, M. Walter, B. Kehrel, U. Seedorf, G. Assmann, Hdl(3) Activates Phospholipase-D in Normal But Not in Glycoprotein lib/liia-Deficient Platelets. Biochem. Biophys. Res. Commun. 207 (1995) 148-154.

[28] M. Elvers, D. Stegner, I. Hagedorn, C. Kleinschnitz, A. Braun, M. E. J. Kuijpers, M.Boesl, Q. Chen, J. W. M. Heemskerk, G. Stoll, M. A. Frohman, B. Nieswandt, Impaired alpha(Ilb)beta(3) Integrin Activation and Shear-Dependent Thrombus Formation in Mice Lacking Phospholipase D1. Sci Signal 3 (2010).

[29] G. W. Du, M. A. Frohman, A Lipid-signaled Myosin Phosphatase Surge Disperses Cortical Contractile Force Early in Cell Spreading. Mol. Biol. Cell 20 (2009) 200-208.

[30] C. Zhao, G. W. Du, K. Skowronek, M. A. Frohman, D. Bar-Sagi, Phospholipase D2-generated phosphatidic acid couples EGFR stimulation to Ras activation by Sos. Nat. Cell Biol. 9 (2007) 706-U171.

[31] N. Vitale, A. S. Caumont, S. Chasserot-Golaz, G. Du, S. Wu, V. A. Sciorra, A. J. Morris, M. A. Frohman, M. F. Bader, Phospholipase D1: a key factor for the exocytotic machinery in neuroendocrine cells. EMBO J. 20 (2001) 2424-2434.

[32] Y. Huang, X. Y. Zhang, H. L. Chen, Regulation of phospholipase D activity in human hepatocacinoma cells by protein kinases and D-sphingosine. Acta Biochim. Biophys. Sin. 31 (1999) 572-576.

[33] A. Garcia, Y. Zheng, C. Zhao, A. Toschi, J. Fan, N. Shraibman, H. A. Brown, D. Bar-Sagi, D. A. oster, J. L. Arbiser, Honokiol suppresses survival signals mediated by Ras-dependent phospholipase D activity in human cancer cells. Clin. Cancer Res. 14 (2008) 4267-4274.

[34] L. Monovich, B. Mugrage, E. Quadros, K. Toscano, R. Tommasi, S. LaVoie, E. Liu, Z.M. Du, D. LaSala, , W. Boyar, P. Steed, Optimization of halopemide for phospholipase D2 inhibition. Bioorg. Med. Chem. Lett. 17 (2007) 2310-2311. 
[35] C. D. Nobes, A. Hall, Rho, Rac, and Cdc42 Gtpases Regulate the Assembly of Multimolecular Focal Complexes Associated with Actin Stress Fibers, Lamellipodia, and Filopodia. Cell 81 (1995) 53-62.

[36] I. Pleines, M. Elvers, A. Strehl, M. Pozgajova, D. Varga-Szabo, F. May, A. Chrostek-Grashoff, C.Brakebusch, B. Nieswandt, Rac1 is essential for phospholipase C-gamma 2 activation in platelets. Pflugers Arch. 457 (2009) 1173-1185.

[37] I. Pleines, A. Eckly, M. Elvers, I. Hagedorn, S. Eliautou, M. Bender, X. W. Wu, F. Lanza, C. Gachet, C. Brakebusch, B. Nieswandt, Multiple alterations of platelet functions dominated by increased secretion in mice lacking Cdc42 in platelets. Blood 115 (2010) 3364-3373.

[38] G. Levin, K. L. Duffin, M. G. Obukowicz, S. L. Hummert, H. Fujiwara, P. Needleman, A. Raz, Differential metabolism of dihomo-gamma-linolenic acid and arachidonic acid by cyclooxygenase-1 and cyclo-oxygenase-2: implications for cellular synthesis of prostaglandin E-1 and prostaglandin E-2. Biochem. J. 365 (2002) 489-496.

[39] Z. Y. Li, G. Y. Zhang, G. C. Le Breton, X. P. Gao, A. B. Malik, X. P. Du, Two waves of platelet secretion induced by thromboxane A(2) receptor and a critical role for phosphoinositide 3kinases. J. Biol. Chem. 278 (2003) 30725-30731.

[40] M. T. Harper, A. W. Poole, Diverse functions of protein kinase $C$ isoforms in platelet activation and thrombus formation. J. Thromb. Haemost. 8 (2010) 454-462.

[41] S. Kim, P. Mangin, C. Dangelmaier, R. Lillian, S. P. Jackson, J. L. Daniel, S. P. Kunapuli, Role of Phosphoinositide 3-Kinase beta in Glycoprotein VI-mediated Akt Activation in Platelets. J. Biol. Chem. 284 (2009) 33763-33772.

[42] T. C. Sung, R. L. Roper, Y. Zhang, S. A. Rudge, R. Temel, S. M. Hammond, A. J. Morris, B. Moss, J. Engebrecht, M. A. Frohman, Mutagenesis of phospholipase D defines a superfamily including a trans-Golgi viral protein required for poxvirus pathogenicity. EMBO J. 16 (1997) 4519-4530.

[43] P. Huang, M. A. Frohman, The potential for phospholipase D as a new therapeutic target. Expert Opin. Ther. Targets 11 (2007) 707-716.

[44] A. Skippen, D. H. Jones, C. P. Morgan, M. Li, S. Cockcroft, Mechanism of ADP ribosylation factor-stimulated phosphatidylinositol 4,5-bisphosphate synthesis in HL60 cells. J. Biol. Chem. 277 (2002) 5823-5831. 
[45] J. R. Coorssen, R. J. Haslam, Gtp-Gamma-S and Phorbol Ester Act Synergistically to Stimulate Both Ca2+-Independent Secretion and Phospholipase-D Activity in Permeabilized Human Platelets - Inhibition by Bapta and Analogs. FEBS Lett. 316 (1993) 170-174.

[46] M. Holinstat, B. Voss, M. L. Bilodeau, H. E. Hamm, Protease-activated receptors differentially regulate human platelet activation through a phosphatidic acid-dependent pathway. Mol. Pharmacol. 71 (2007) 686-694.

[47] L. Waselle, R. R. L. Gerona, N. Vitale, T. F. J. Martin, M. F. Bader, R. Regazzi, Role of phosphoinositide signaling in the control of insulin exocytosis. Mol. Endocrinol. 19 (2005) 3097-3106.

[48] L. C. Chang, T. H. Huang, C. S. Chang, Y. R. Tsai, R. H Lin, P. W. Lee, M. F. Hsu, L. J. Huang, J. P. Wang, Signaling mechanisms of inhibition of phospholipase D activation by CHS111 in formyl peptide-stimulated neutrophils. Biochem. Pharmacol. 81 (2011) 269-278.

[49] S. A. Rudge, M. J. O. Wakelam, Inter-regulatory dynamics of phospholipase D and the actin cytoskeleton. Biochim. Biophys. Acta 1791 (2009) 856-861.

[50] Y. Banno, Regulation and possible role of mammalian phospholipase D in cellular functions. Biochem. J. 131 (2002) 301-306.

[51] T. Sumi, K. Matsumoto, T. Nakamura, Specific activation of LIM kinase 2 via phosphorylation of threonine 505 by ROCK, a rho-dependent protein kinase. J. Biol. Chem. 276 (2001) 670676.

[52] L. Han, M. B. Stope, M. L. de Jesus, P. A. O. Weernink, M. Urban, T. Wieland, D. Rosskopf, K. Mizuno, K. H. Jakobs, M. Schmidt, Direct stimulation of receptor-controlled phospholipase D1 by phospho-cofilin. EMBO J. 26 (2007) 4189-4202.

[53] M. S. Xie, L. S. Jacobs, G. R. Dubyak, Regulation of Phospholipase-D and Primary Granule Secretion by P2-Purinergic-Receptor and Chemotactic Peptide-Receptor Agonists Is Induced During Granulocytic Differentiation of HI-60 Cells. J. Clin. Invest. 88 (1991) 45-54.

[54] A. Fensome, E. Cunningham, S. Prosser, S. K. Tan, P. Swigart, G. Thomas, J. Hsuan, S. Cockcroft, ARF and PITP restore GTP gamma S-stimulated protein secretion from cytosoldepleted HL60 cells by promoting PIP2 synthesis. Curr. Biol. 6 (1996) 730-738. 
[55] D. H. Jones, B. Bax, A. Fensome, S. Cockcroft, ADP ribosylation factor 1 mutants identify a phospholipase D effector region and reveal that phospholipase D participates in lysosomal secretion but is not sufficient for recruitment of coatomer I. Biochem. J. 341 (1999) 185-192.

[56] M. Emoto, J. K. Klarlund, S. B. Waters, V. Hu, J. M. Buxton, A. Chawla, M. P. Czech, A role for phospholipase D in GLUT4 glucose transporter translocation. J Biol. Chem. 275 (2000) 7144-7151.

[57] W. E. Hughes, Z. Elgundi, P. Huang, M. A. Frohman, T. J. Biden, Phospholipase D1 regulates secretagogue-stimulated insulin release in pancreatic beta-cells. J. Biol. Chem. 279 (2004) 27534-27541.

[58] W. S. Choi, Y. M. Kim, C. Combs, M. A. Frohman, M. A. Beaven, Phospholipases D1 and D2 regulate different phases of exocytosis in mast cells. J. Immunol. 168 (2002) 5682-5689.

[59] H. X. Qin, M. A. Frohman, W. B. Bollag, Phospholipase D2 Mediates Acute Aldosterone Secretion in Response to Angiotensin II in Adrenal Glomerulosa Cells. Endocrinology 151 (2010) 2162-2170.

[60] D. Toullec, P. Pianetti, H. Coste, P. Bellevergue, T. Grandperret, M. Ajakane, V. Baudet, P. Boissin, E. Boursier, F. Loriolle, L. Duhamel, D. Charon, J. Kirilovsky, The Bisindolylmaleimide Gf-109203X Is A Potent and Selective Inhibitor of Protein-Kinase-C. J. Biol. Chem. 266 (1991) 15771-15781.

[61] Y. Watanabe, M. Ito, Y. Kataoka, H. Wada, M. Koyama, J. H. Feng, H. Shiku, M. Nishikawa, Protein kinase C-catalyzed phosphorylation of an inhibitory phosphoprotein of myosin phosphatase is involved in human platelet secretion. Blood 97 (2001) 3798-3805.

[62] O. Konopatskaya, K. Gilio, M. T. Harper, Y. Zhao, J. M. E. M. Cosemans, Z. A. Karim, S. W. Whiteheart, J. D. Molkentin, P. Verkade, S. P. Watson, J. W. M. Heemskerk, , A. W. Poole, PKC alpha regulates platelet granule secretion and thrombus formation in mice. J. Clin. Invest. 119 (2009) 399-407.

[63] G. Pula, K. Schuh, U. Walter, K. I. Nakayama, K. Nakayama, A. W. Poole, PKC delta regulates platelet activity through the inhibition of VASP-Mediated filopodia formation. Blood 108 (2006) 436A. 
[64] A. M. McDermott, R. J. Haslam, Chemical cross-linking of pleckstrin in human platelets:

Evidence for oligomerization of the protein and its dissociation by protein kinase C. Biochem. J. 317 (1996) 119-124.

[65] J. S. Chen, J. H. Exton, Regulation of phospholipase D2 activity by protein kinase C alpha. J. Biol. Chem. 279 (2004) 22076-22083.

[66] T. C. Sung, Y. Zhang, A. J. Morris, M. A. Frohman, Structural analysis of human phospholipase D1. J. Biol. Chem. 274 (1999) 3659-3666.

[67] T. C. Sung, Y. M. Altshuller, A. J. Morris, M. A. Frohman, Molecular analysis of mammalian phospholipase d2. J. Biol. Chem. 274 (1999) 494-502.

[68] V. A. Sciorra, S. A. Rudge, G. D. Prestwich, M. A. Frohman, J. Engebrecht, ,A. J. Morris, Identification of a phosphoinositide binding motif that mediates activation of mammalian and yeast phospholipase D isoenzymes. EMBO J. 18 (1999) 5911-5921.

[69] C. Dall'Armi, A. Hurtado-Lorenzo, H. Tian, E. Morel, A. Nezu, R.B. Chan, W.H. Yu, K.S. Robinson, O. Yeku, S.A. Small, K. Duff, M.A. Frohman, M.R. Wenk, A. Yamamoto, G. Di Paolo, The phospholipase D1 pathway modulates macroautophagy. Nat Commun. 1 (2010) 142. 
A

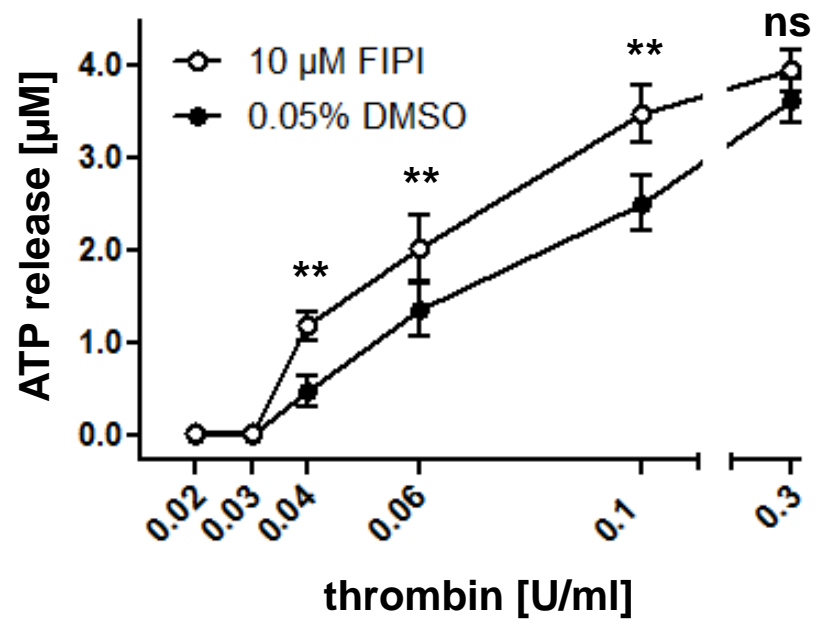

B

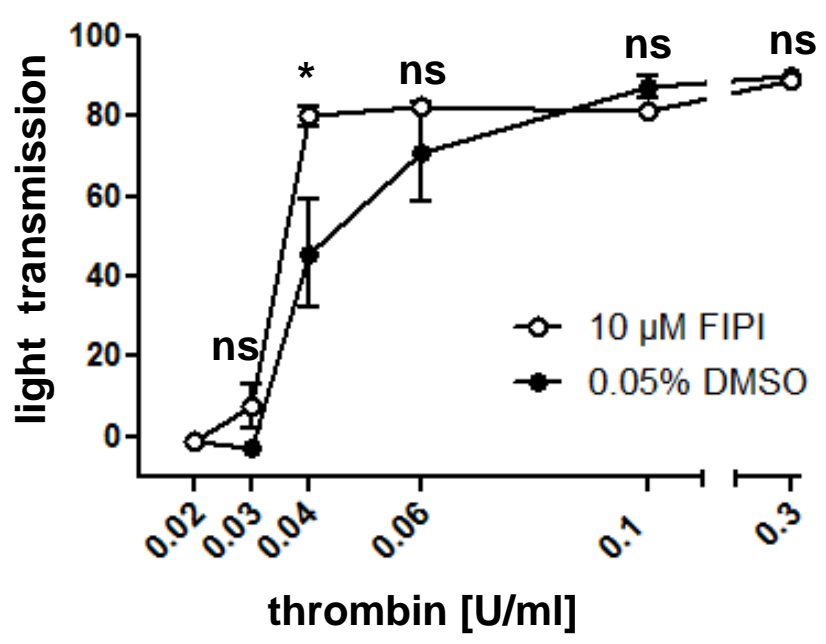

C

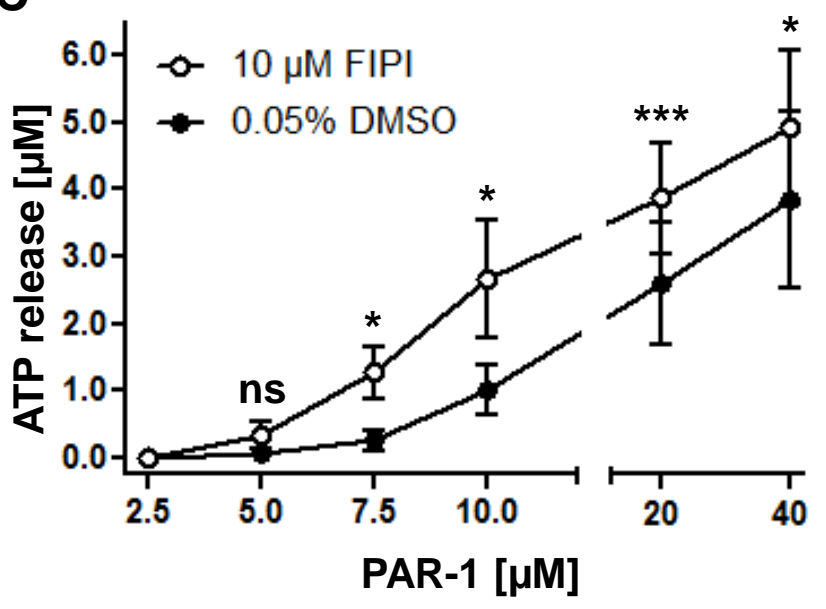

D

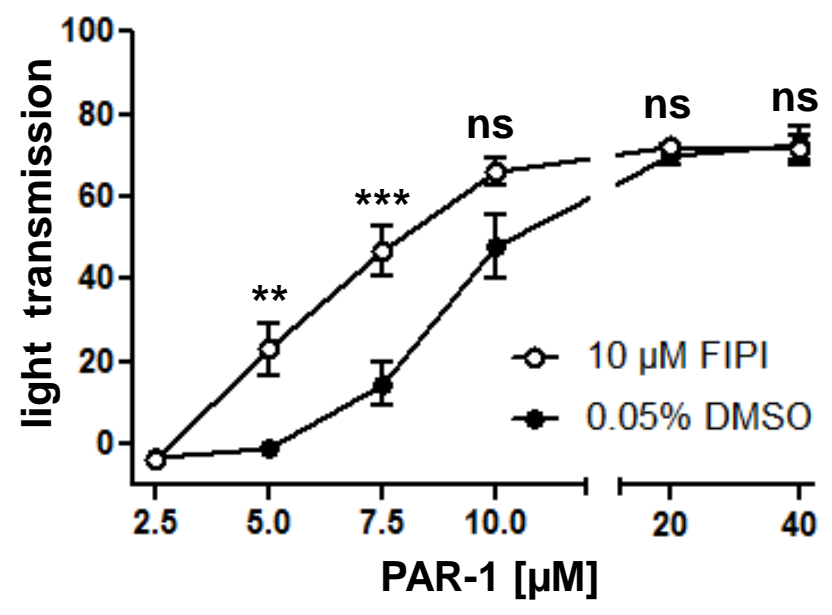



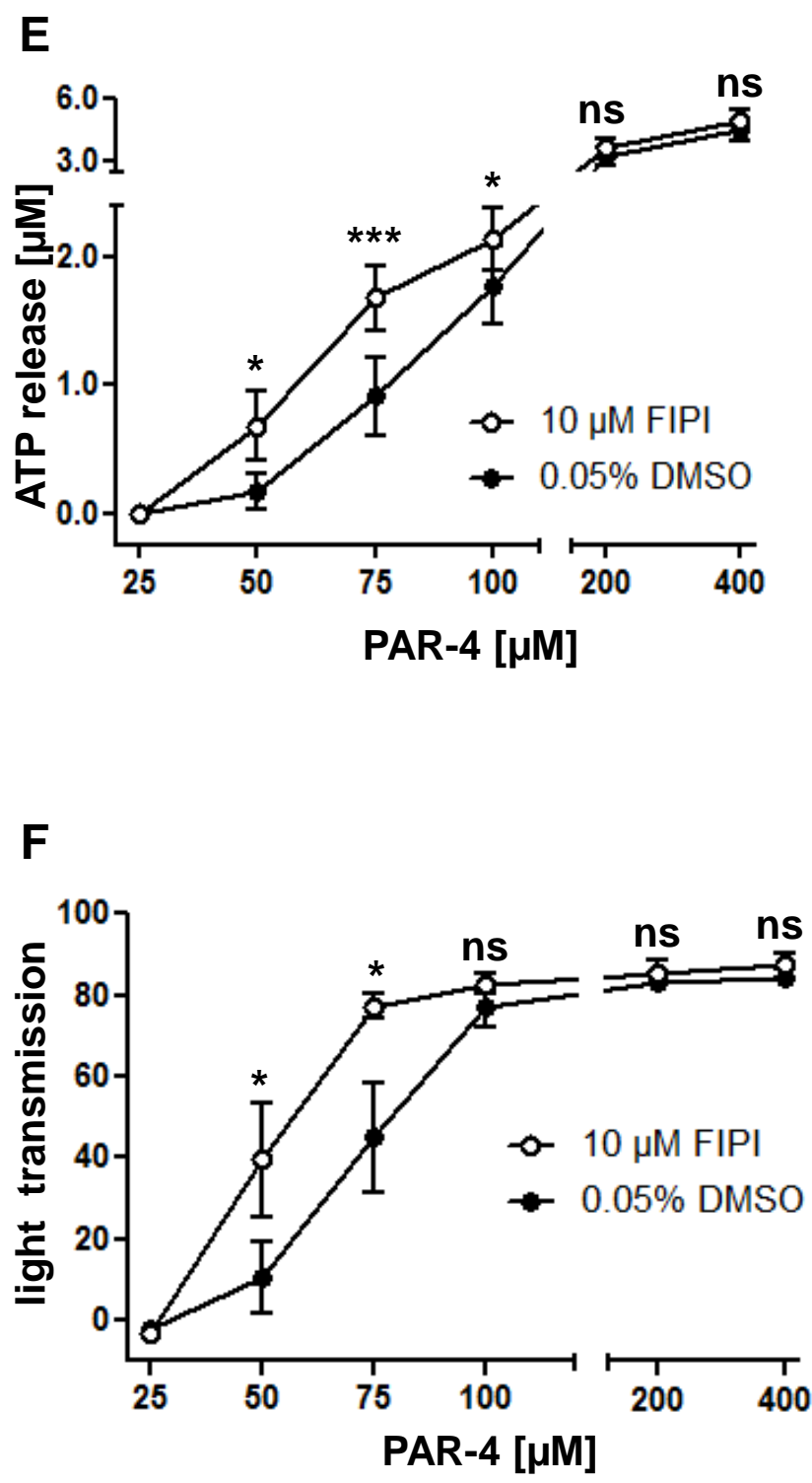

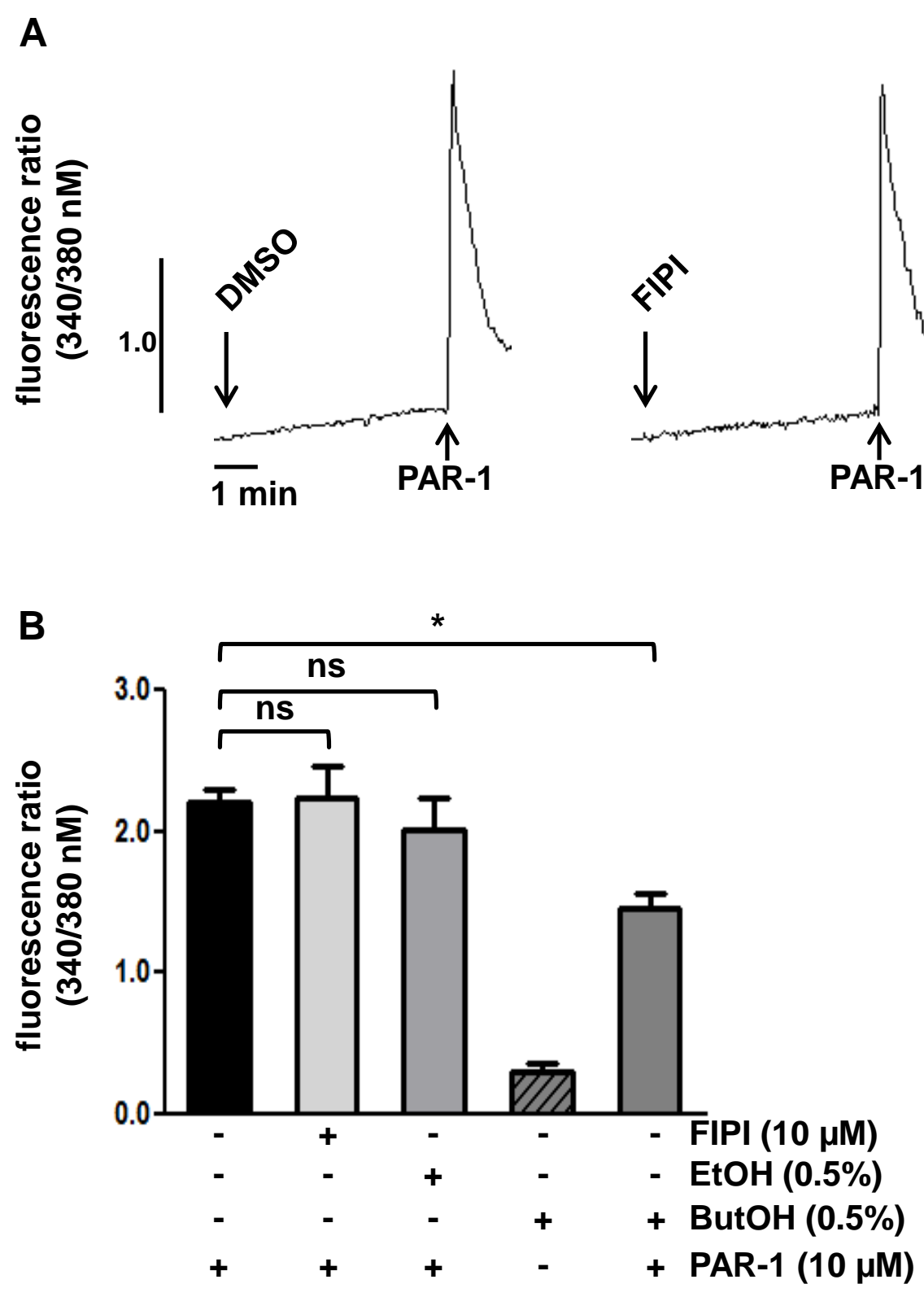
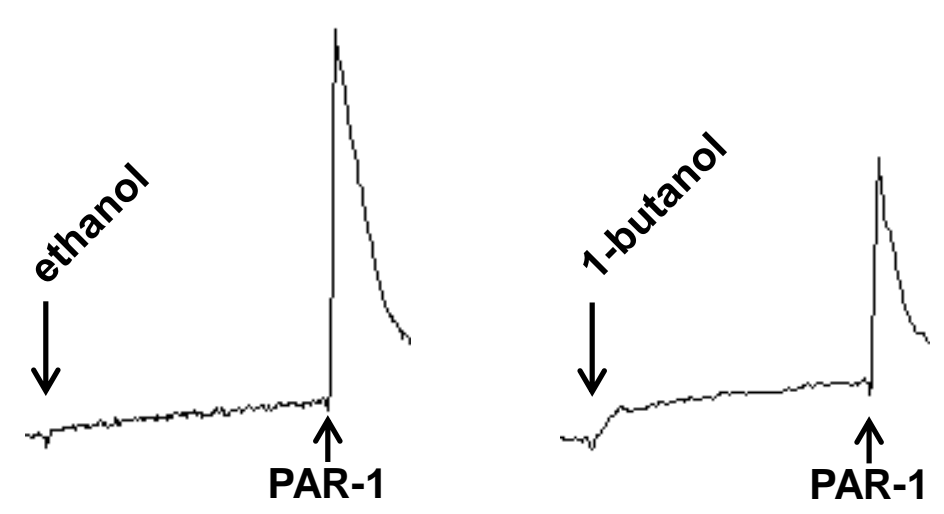

C

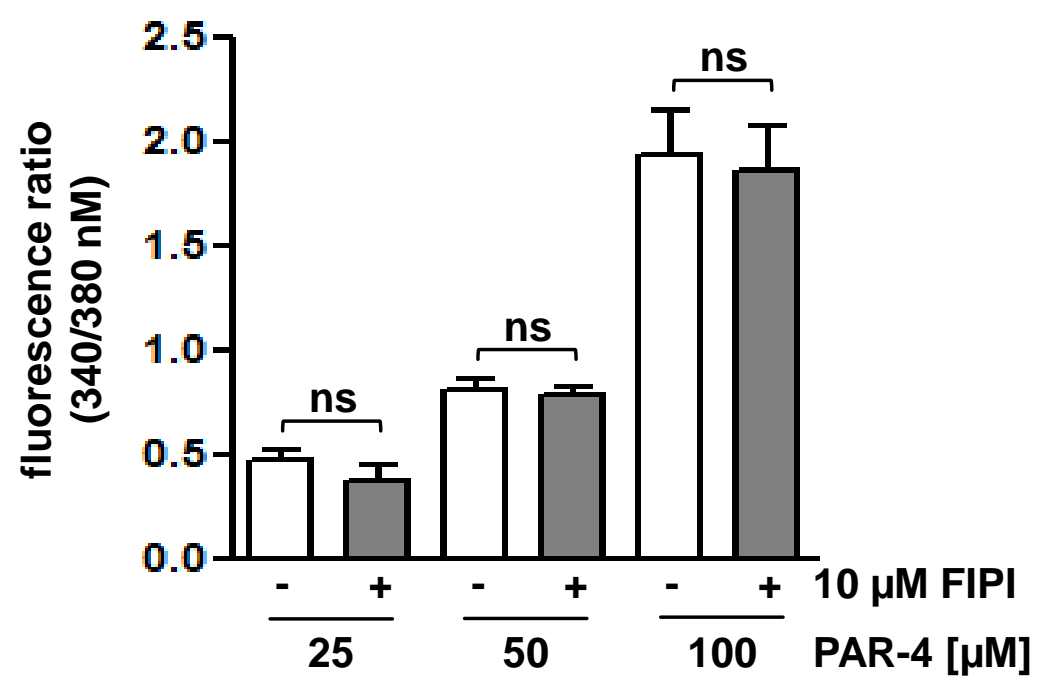


A
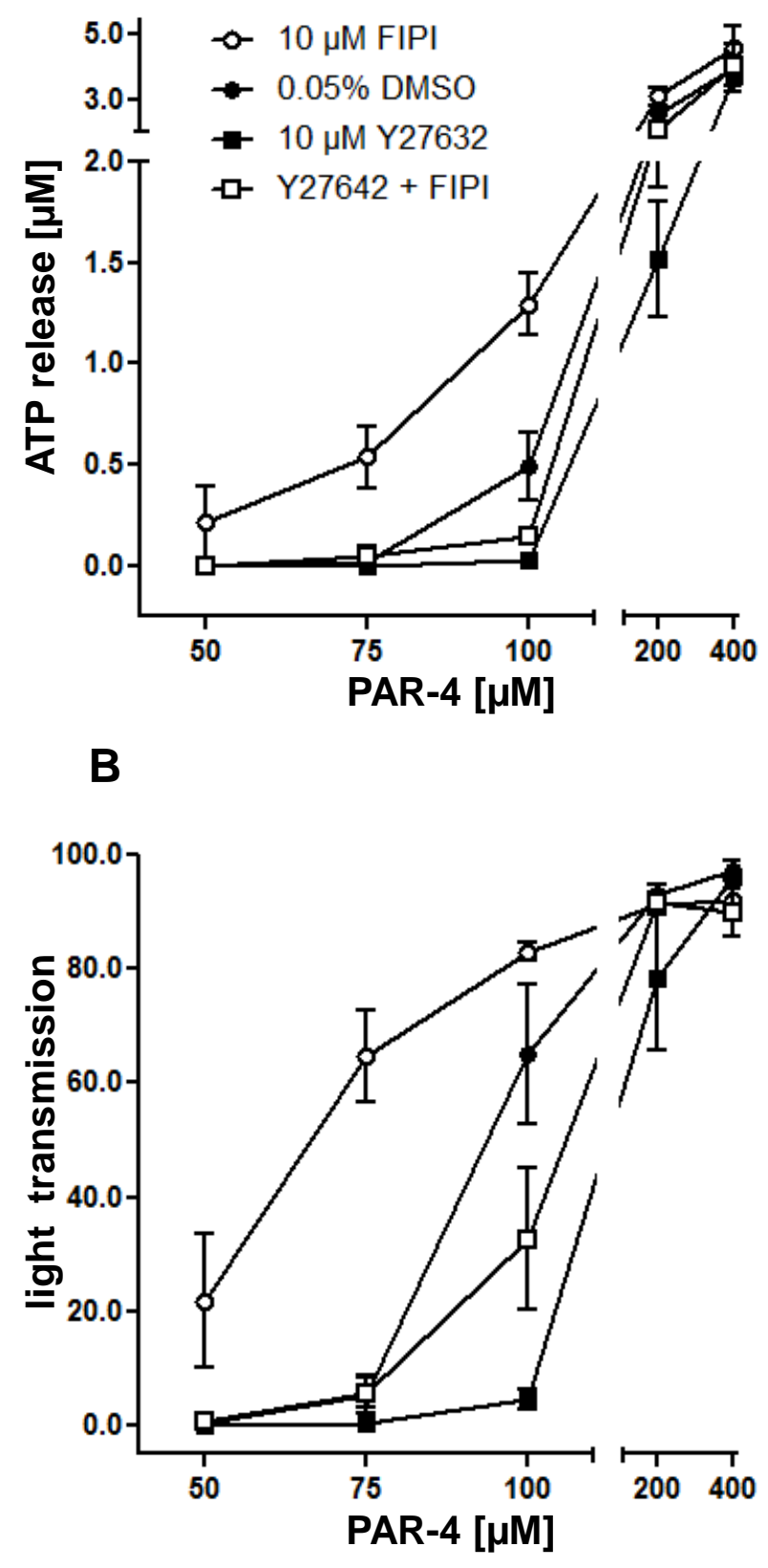

\section{MLC phosphorylation}

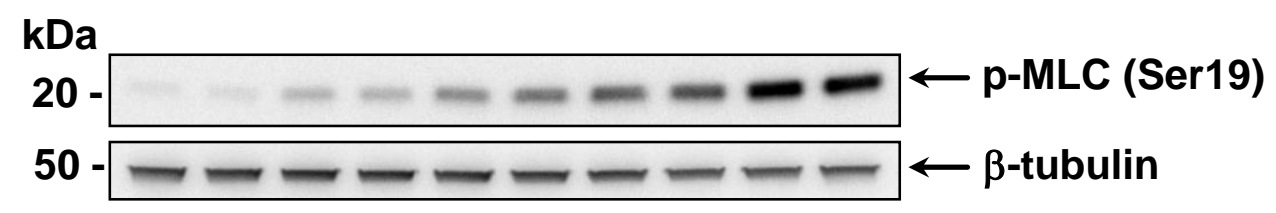

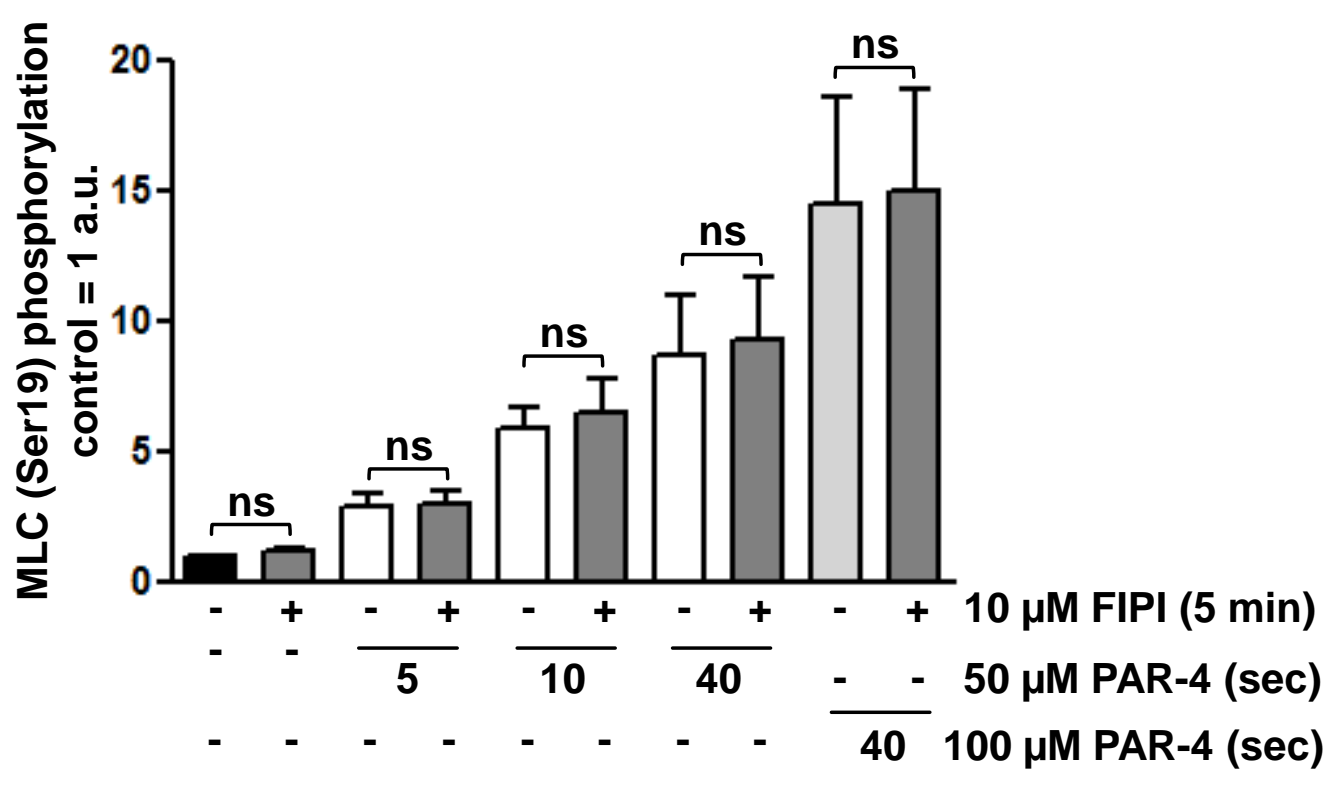


A ATP release

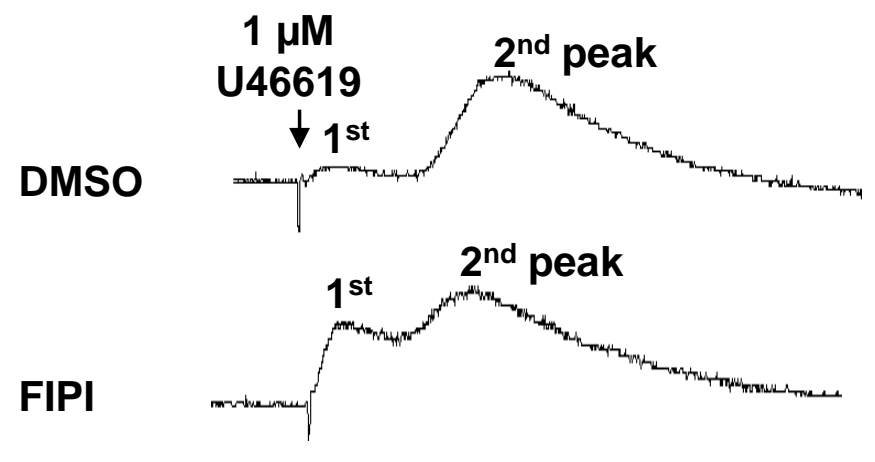

FIPI + cangrelor

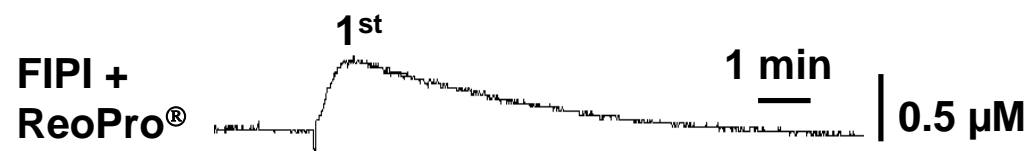

B Aggregation

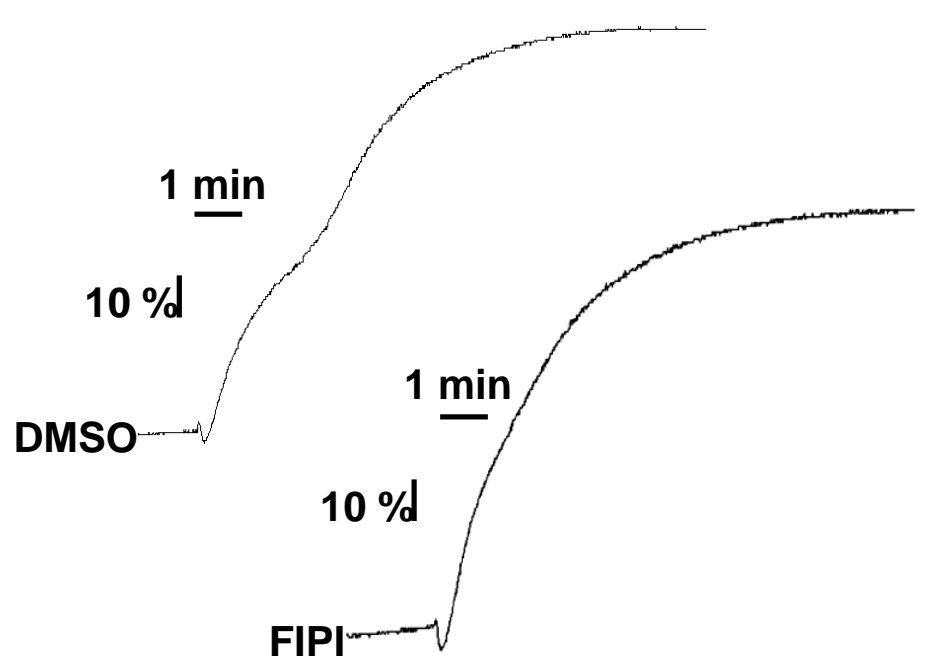

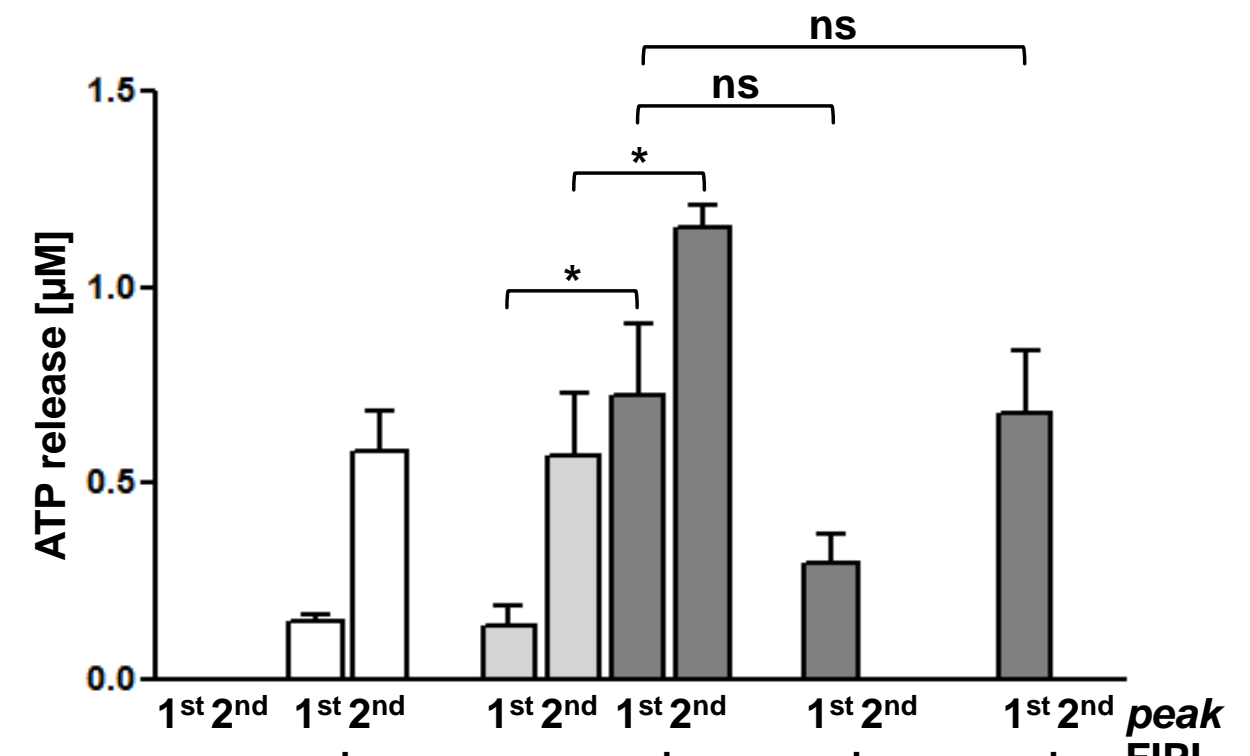

+ FIPI

- cangrelor

+ ReoPro $^{\circledR}$

$\begin{array}{lllllll}0.5 & 0.5 & 1.0 & 1.0 & 1.0 & 1.0 & \text { U46619 }[\mu M]\end{array}$

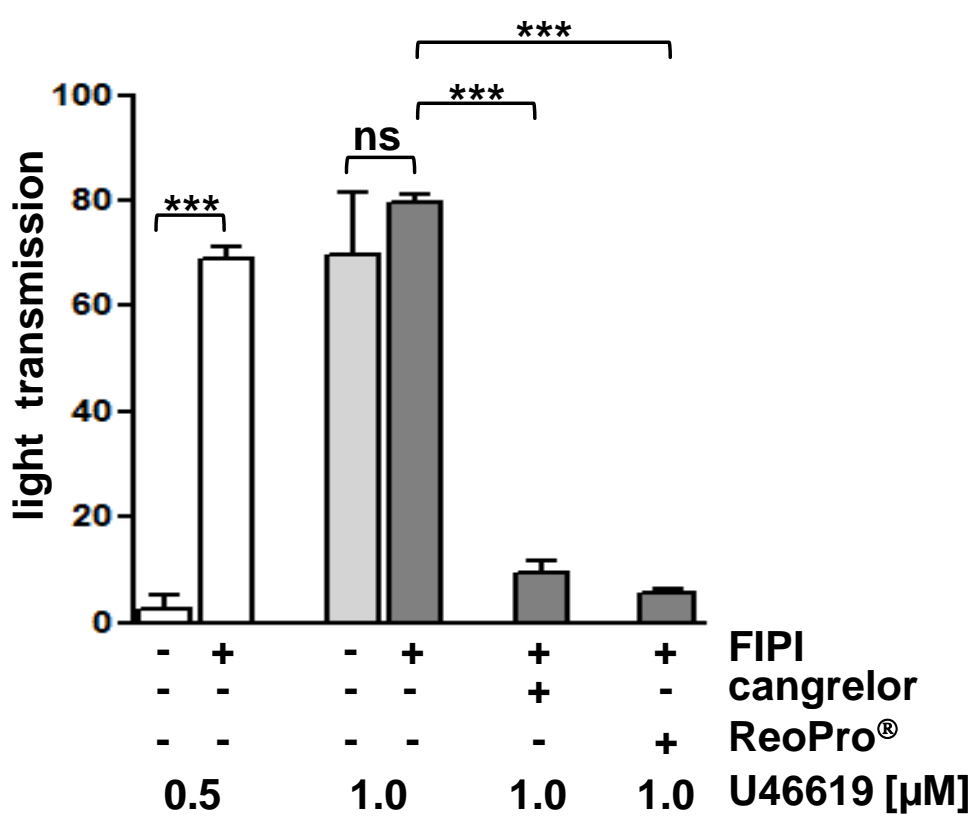


A

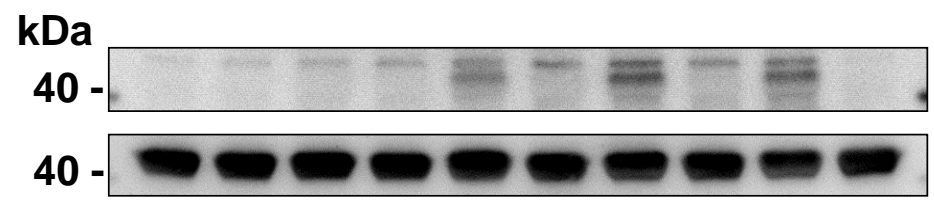

B

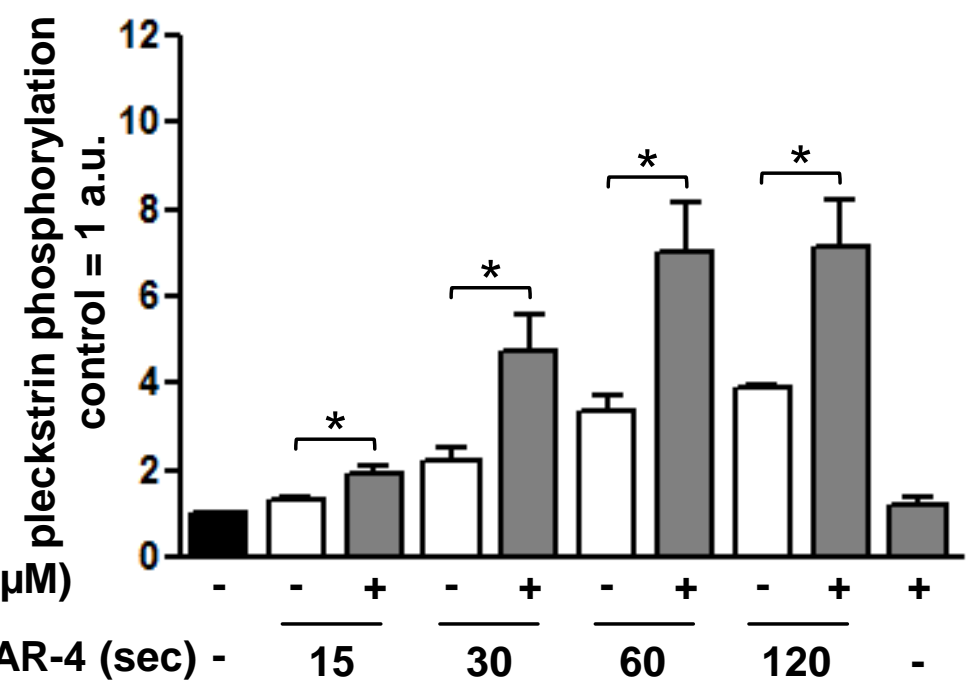

C

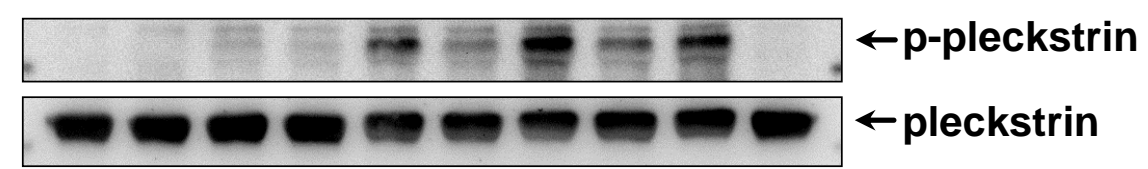

FIPI (10 $\mu \mathrm{M})$

$50 \mu \mathrm{M}$ PAR-4 (sec) -
D

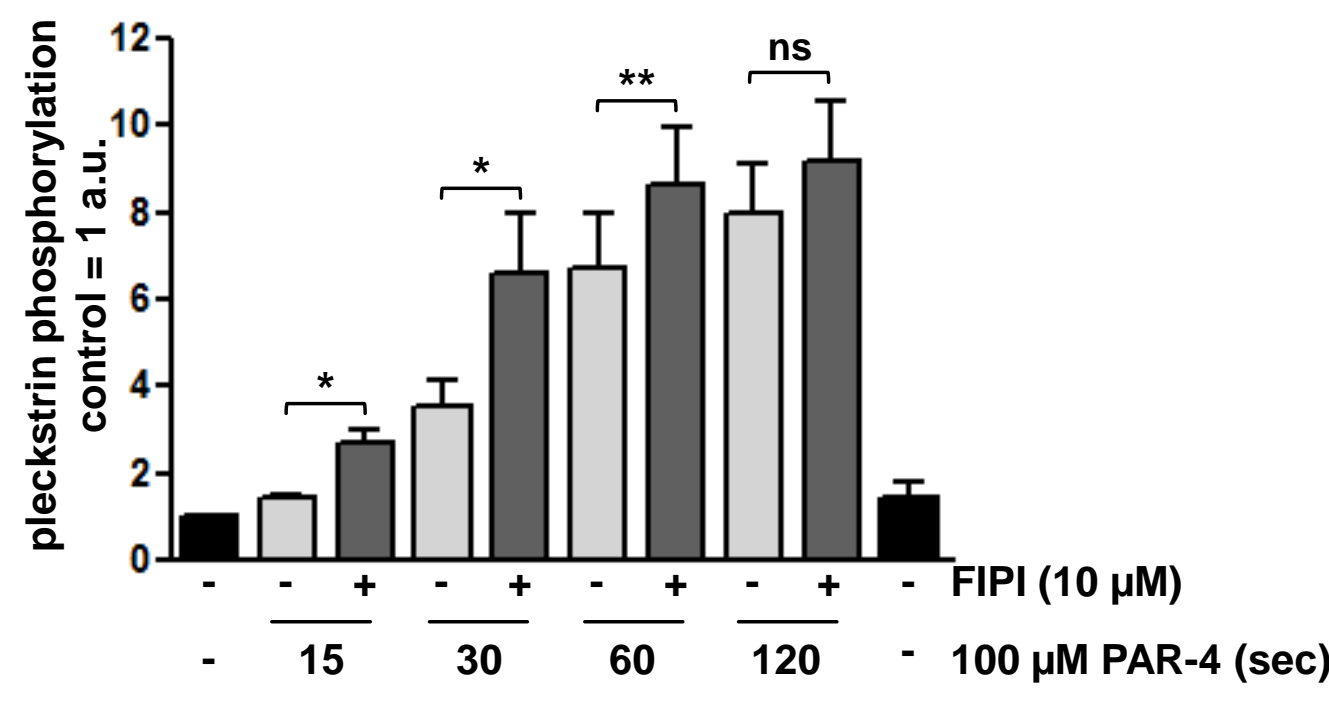


Piqgé 6

A

wild-type

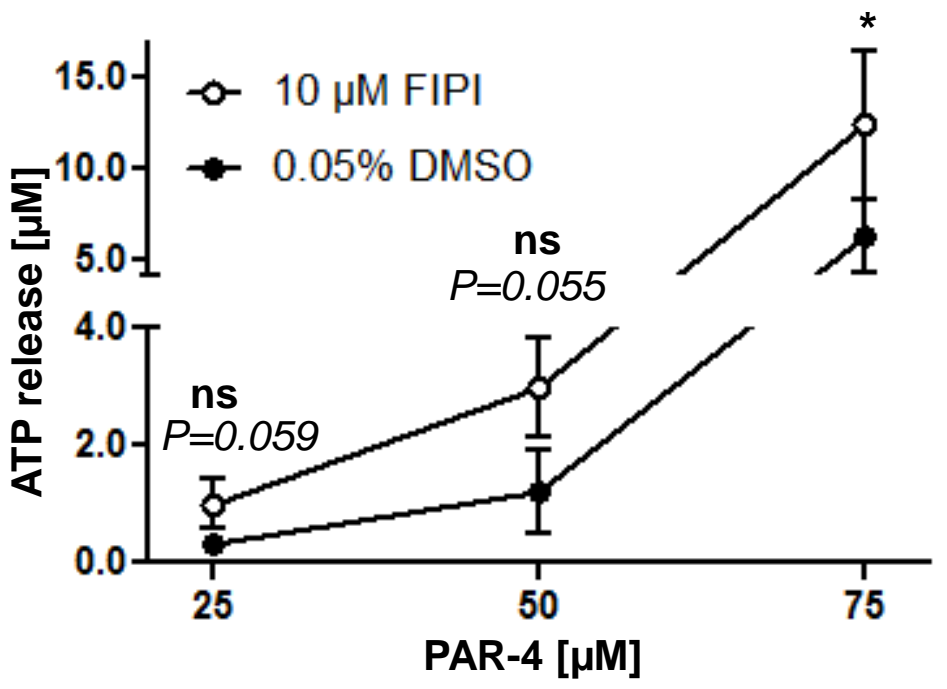

B

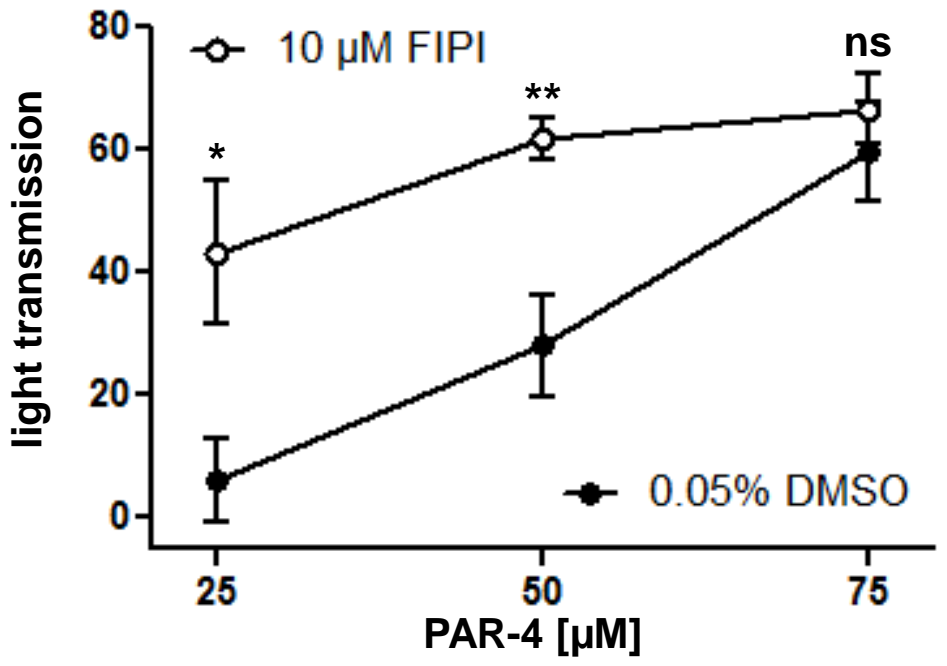

C

PId1 $^{-/}$

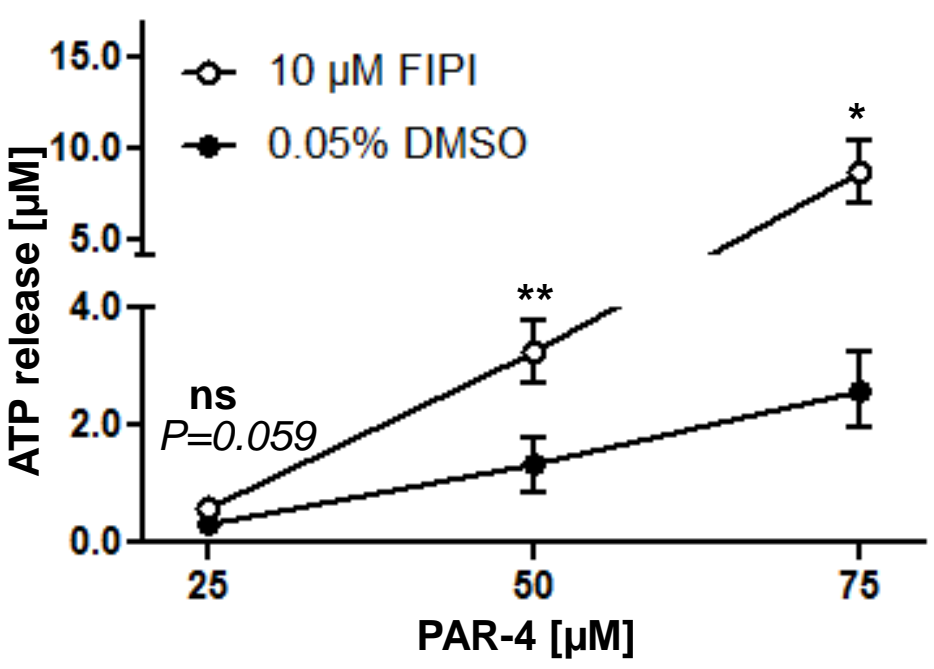

D

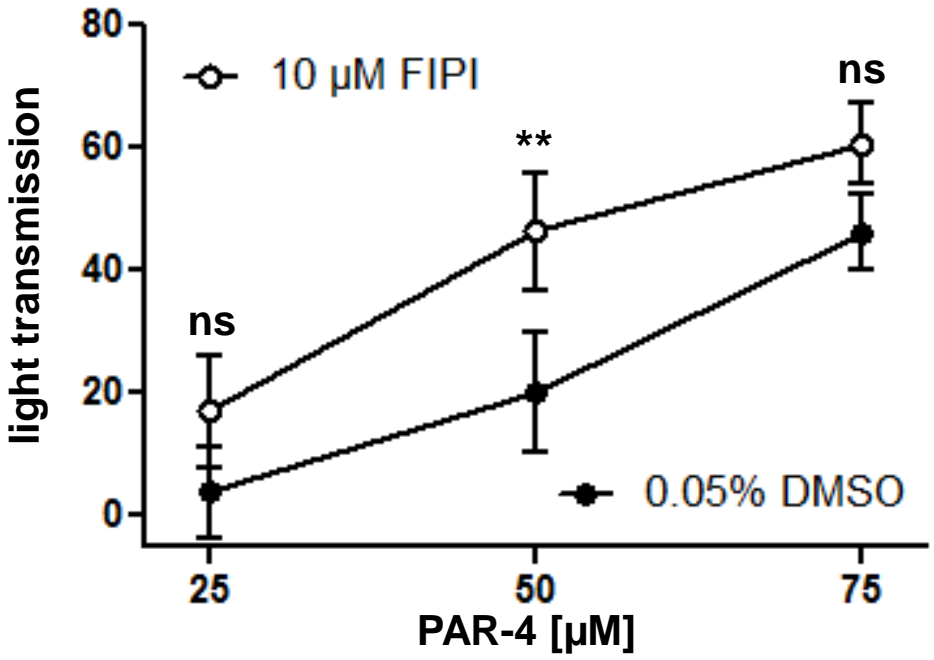


Supplementary Data
Click here to downloa

Click here to download Supplementary Material: Elvers et al_Supplementary Data.doc (2)

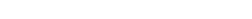

(1)
(1) (1) (1) (1) (1) .

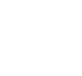

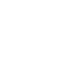

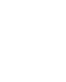

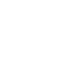

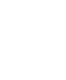

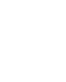

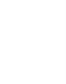

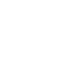

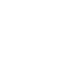

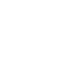
更

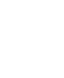

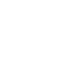

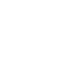

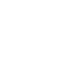
. 